\title{
Dispersion of deep-sea hydrothermal vent effluents and larvae by submesoscale and tidal currents
}

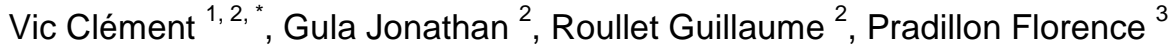

${ }^{1}$ Department of Ocean and Earth Sciences, University of Southampton, Southampton, United Kingdom

${ }^{2}$ Univ. Brest, CNRS, IRD, Ifremer, Laboratoire d'Océanographie Physique et Spatiale (LOPS), IUEM, Brest, France

${ }^{3}$ IFREMER, Centre Brest, REM/EEP/LEP, Institut Carnot Ifremer-EDROME, Plouzané, France

* Corresponding author : Clément Vic, email address : c.vic@soton.ac.uk

\begin{abstract}
:
Deep-sea hydrothermal vents provide sources of geochemical materials that impact the global ocean heat and chemical budgets, and support complex biological communities. Vent effluents and larvae are dispersed and transported long distances by deep ocean currents, but these currents are largely undersampled and little is known about their variability. Submesoscale $(0.1-10 \mathrm{~km})$ currents are known to play an important role for the dispersion of biogeochemical materials in the ocean surface layer, but their impact for the dispersion in the deep ocean is unknown. Here, we use a series of nested regional oceanic numerical simulations with increasing resolution (from $\delta x=6 \mathrm{~km}$ to $\delta x=0.75 \mathrm{~km}$ ) to investigate the structure and variability of highly-resolved deep currents over the Mid-Atlantic Ridge (MAR) and their role on the dispersion of the Lucky Strike hydrothermal vent effluents and larvae. We shed light on a submesoscale regime of oceanic turbulence over the MAR at $1500 \mathrm{~m}$ depth, contrasting with openocean - i.e., far from topographic features - regimes of turbulence, dominated by mesoscales.

Impacts of submesoscale and tidal currents on larval dispersion and connectivity among vent populations are investigated by releasing neutrally buoyant Lagrangian particles at the Lucky Strike hydrothermal vent. Although the absolute dispersion is overall not sensitive to the model resolution, submesoscale currents are found to significantly increase both the horizontal and vertical relative dispersion of particles at $\mathrm{O}(1-10) \mathrm{km}$ and $\mathrm{O}(1-10)$ days, resulting in an increased mixing of the cloud of particles. A fraction of particles are trapped in submesoscale coherent vortices, which enable transport over long time and distances. Tidal currents and internal tides do not significantly impact the horizontal relative dispersion. However, they roughly double the vertical dispersion. Specifically, particles undergo strong tidally-induced mixing close to rough topographic features, which allows them to rise up in the water column and to cross topographic obstacles.
\end{abstract}

The mesoscale variability controls at first order the connectivity between hydrothermal sites and we do not have long enough simulations to conclude on the connectivity between the different MAR hydrothermal sites. However, our simulations suggest that the connectivity might be increased by submesoscale and tidal currents, which act to spread the cloud of particles and help them cross 
topographic barriers.

\section{Highlights}

- High-resolution numerical simulations shed light on a submesoscale regime of turbulence at the depth of the Mid-Atlantic Ridge. Submesoscale and tidal currents enhance the relative dispersion of particles and might augment the likelihood of connectivity between MAR hydrothermal vents. Tidal currents and internal tides double the vertical dispersion of particles and help crossing topographic barriers.

Keywords: Submesoscales, Tides, Hydrothermal vent, Lagrangian dispersion, Lucky Strike, MidAtlantic Ridge, Connectivity, Bathymodiolus 


\section{Introduction}

Hydrothermal vents form along mid-ocean ridges where tectonic plates diverge. They are unique sites with strong biogeochemical activity (e.g., iron source, Conway and John, 2004) and ecological settings contrasting with the

5 surrounding abyssal landscape (Van Dover, 1995, 2000). As such, Mid-Atlantic Ridge (MAR) hydrothermal vent sites have been extensively sampled. In particular, the Lucky Strike vent field $\left(37.30^{\circ} \mathrm{N}, 32.28^{\circ} \mathrm{W}\right)$ has been chosen by the European Multidisciplinary Subsea and water column Observatory (EMSO) to be a prototype for environmental monitoring. However, dedicated cruises have

10 limited spatial coverage $\left(<10 \times 10 \mathrm{~km}^{2}\right.$, e.g., Escartin et al., 2015) and focus 
on vents themselves and their associated near-field convective plumes. Consequently, the fate of released effluents in the far-field $(>1-10$ days and $>10 \mathrm{~km}$ ) remains uncertain. Yet several questions of biological and (bio)geochemical relevance need to be addressed, e.g., which processes control the transport and mixing of vent effluents? Can vent faunal communities be connected through larval transport at ecologically-relevant time scales?

Dispersion and connectivity issues are fundamentally multi-scale, from larval behavioural characteristics (vertical migration and change in buoyancy) to advection by basin-scale currents. Increasing the resolution of reef-scale models (Werner et al., 2007) to 0.1-1 km have demonstrated a significant improvement of the realism of physical processes related to interactions with topography, tidally-driven and small-scale currents. As such, the realism of Lagrangian dispersion and connectivity patterns has been improved, unveiling new perspectives on the functioning of reef ecosystems (Bode et al., 2006; Werner et al., 2007).

${ }_{25}$ However, this range of resolutions have not been reached so far in the context of deep-sea connectivity.

Oceanic submesoscale $(0.1-10 \mathrm{~km})$ processes have been extensively studied during the past decade, but most of the effort has been focused on the surface boundary layer (e.g., Buckingham et al., 2017). They are particularly energetic so and have multiple implications on the oceanic state (See review in McWilliams, 2016). Among their implications, surface submesoscale currents strongly impact the transport and mixing of tracers in the surface layer (e.g., Poje et al., 2014; Haza et al., 2016), as well as the dynamics of planktonic organisms, including dispersing larval stages (Sponaugle et al., 2005; Mullaney and Suthers, 2013), 35 and thus connectivity patterns of benthic populations on continental shelves.

Conversely, submesoscale turbulence in the ocean interior (below the surface mixed layer) remains poorly studied although it has been observed in the form of submesoscale vortices since the 1980s (McWilliams, 1985; D'Asaro, 1988; Testor and Gascard, 2003; Bosse et al., 2015, 2016, 2017). At the depth of mid-ocean

40 ridges (i.e., 1000-3000 m), observations of submesoscale currents are rare. Far from boundary currents, the ocean is still widely believed to be very quiescent at 
these scales, although float trajectories (Reverdin et al., 2009; Bower et al., 2013) and mooring measurements (Lilly et al., 2003) have gathered evidence for locally strong submesoscale flows. Recent modelling studies confirm the existence of 45 submesoscale turbulence in the ocean interior and point out current-topography frictional interactions close to the shelf break $(100-500 \mathrm{~m})$ as a source for this turbulence (Dewar et al., 2015; Gula et al., 2015b, 2016; Molemaker et al., 2015; Vic et al., 2015). Similarly to their role at the surface, submesoscale flows at depth play a role in tracer dispersion, as recently shown in numerical experiments in the Gulf of Mexico (Bracco et al., 2016; Cardona et al., 2016).

Although tidal currents are weak in the deep ocean, they are locally enhanced over mid-ocean ridges. Over the MAR in the North Atlantic, barotropic tidal currents are dominated by the semi-diurnal frequency $\mathrm{M}_{2}$ and reach $3-5 \mathrm{~cm} \mathrm{~s}^{-1}$ (as inferred from TPXO7.2, Egbert and Erofeeva, 2002). The interaction of the barotropic tide with the rough topography of the MAR generates strong internal tides - i.e., internal waves at tidal frequencies - that are responsible for high levels of mixing (St. Laurent and Garrett, 2002; Vic et al., 2017). However, tidal impact on Lagrangian dispersion in the deep ocean has not been documented. ${ }^{1}$

The objectives of this paper are twofold : (i) we aim to characterize submesoscale and tidal currents over the MAR and (ii) investigate their impact on the dispersion of the Lucky Strike hydrothermal vent effluents and larvae. To address these objectives, we set up a series of nested regional primitiveequation simulations and performed Lagrangian dispersion experiments at two different horizontal resolutions, $6 \mathrm{~km}$ and $0.75 \mathrm{~km}$. The latter resolution allows

to make a step forward in the range of resolved scales, comparatively to numerical models dedicated to deep-sea Lagrangian studies (e.g., Breusing et al., 2016, recently used a 5-km resolution model of the MAR). Furthermore, the domain covers a large area $\left(1500 \times 1500 \mathrm{~km}^{2}\right)$ that allows to get a widespread picture of currents at different scales and perform Lagrangian advection over

\footnotetext{
${ }^{1}$ Tidal impact on Lagrangian dispersion has been more examined on continental shelves where tides often dominate advective processes (e.g., Geyer and Signell, 1992).
} 
several months. The configuration at $0.75-\mathrm{km}$ resolution is run with and without a realistic barotropic tidal forcing in order to assess the impact of tides on Lagrangian dispersion. Overall, this study adds insights on key processes governing Lagrangian dispersion in the deep ocean over mid-ocean ridges.

The paper is organized as follows. The model setup is presented in section 2 .

75 A characterization of dynamical regimes on/off the MAR and with/without tides is carried out in section 3 . Observational datasets are used to assess the model capability to generate realistic fields. In section 4, Lagrangian dispersion regimes are investigated, and connectivity issues are discussed in section 5. Conclusions are drawn in section 6.

\section{Numerical framework}

We use the hydrostatic primitive-equation Regional Oceanic Modeling System (ROMS, Shchepetkin and McWilliams, 2005) in a series of one-way nested simulations, following the procedure in Mason et al. (2010). The use of a sigma coordinate system with significant grid stretching at the bottom allows to accurately resolve flow interactions with the seafloor (e.g., Molemaker et al., 2015). The coarsest simulation covers most of the Atlantic Ocean and has a mean horizontal resolution of $\delta x=6 \mathrm{~km}$. It is extensively described in Gula et al. (2015a) and referred to hereafter as ROMS6. Two successive grid refinements are performed with horizontal resolutions of $\delta x=2 \mathrm{~km}$ (ROMS2) and $\delta x=0.75 \mathrm{~km}$ (ROMS0.75 without tides and ROMS0.75T with tides). Domains are shown in Figure 1a. ROMS2 is used as a buffer between the low and high-resolution simulations, in order to maintain a grid refinement coefficient $\left(\delta x_{\text {parent }} / \delta x_{\text {child }}\right)$ around 3 (Debreu and Blayo, 2008).

The ROMS0.75(T) $($ ROMS6) grid has $2000 \times 2000(2000 \times 1500)$ points on the horizontal and 80 (50) vertical levels with stretching parameters $\theta_{s}=6$ and $\theta_{b}=4$. We use a quadratic bottom stress parameterization $\tau=\rho_{0} C_{D}\|\mathbf{u}\| \mathbf{u}$, where $\rho_{0}$ is a reference density and $\mathbf{u}$ is the bottom layer horizontal velocity. The drag coefficient $C_{D}$ uses the Von Karman-Prandtl logarithmic formulation 
$C_{D}=\left[\kappa / \log \left(\Delta z_{b} / z_{r}\right)\right]^{2}$, where $\kappa=0.41$ is the Von Karman constant, $\Delta z_{b}$ is the

\footnotetext{
${ }^{2}$ Notice that the vertical CFL condition is more limiting than the horizontal CFL condition imposed by $\delta x=0.75 \mathrm{~km}$ and maximum model horizontal velocities of $1 \mathrm{~m} \mathrm{~s}^{-1}$.
} 


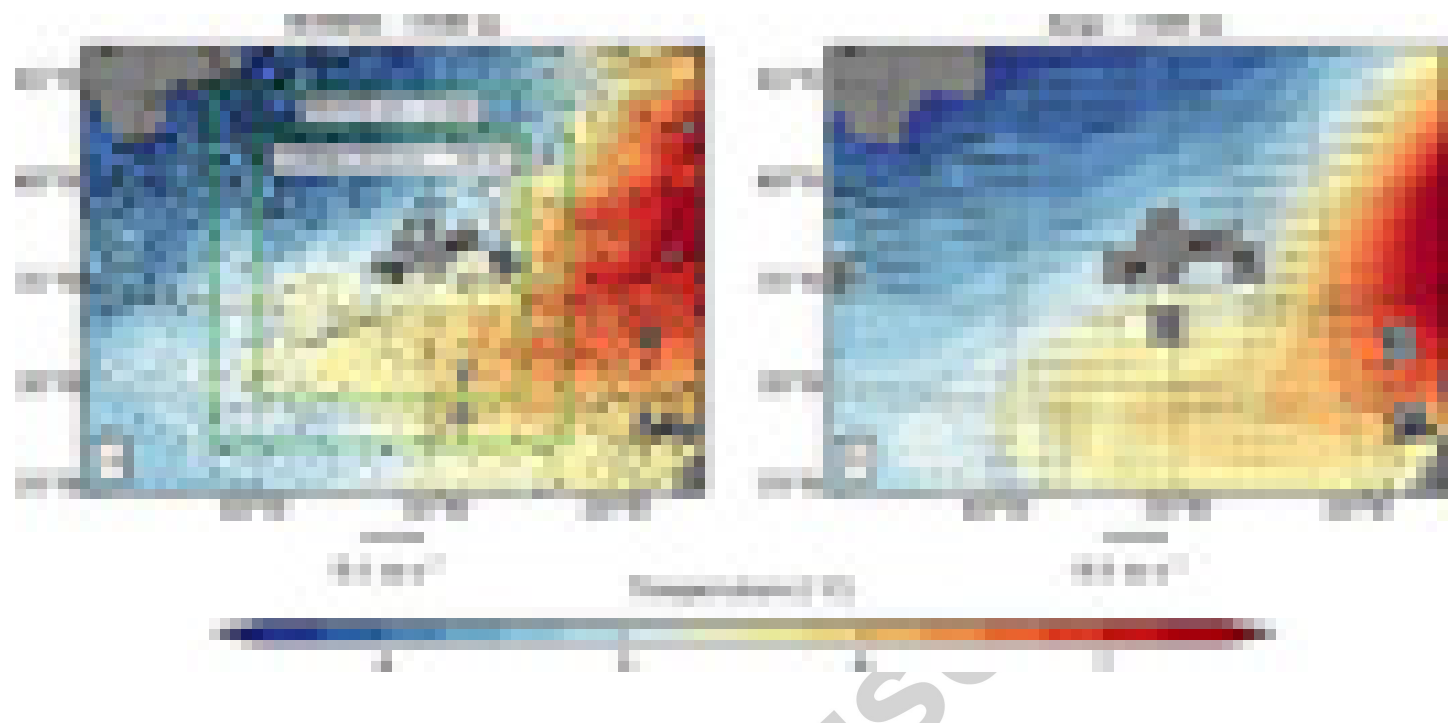

Figure 1: Mean horizontal currents and temperature at $1500 \mathrm{~m}$ from (a) ROMS6 simulation and (b) ANDRO dataset (currents are derived from Argo float trajectories at parking depth and reconstructed in the vertical assuming thermal wind balance, Ollitrault and Rannou, 2013; Colin de Verdière and Ollitrault, 2016). Green lines in (a) are the boundaries of nested simulations ROMS2 $(\delta x=2 \mathrm{~km})$ and ROMS0.75 and ROMS0.75T $(\delta x=0.75 \mathrm{~km})$. Black star is the Lucky Strike site.

The model produces realistic upper ocean mean state and variability. Surface mean currents and variability (Eddy Kinetic Energy, EKE) from ROMS6 and ROMS2 compare well with satellite altimetry products (not shown, see Gula et al., 2015a; Renault et al., 2016, for simulations very similar to ROMS6). Evaluating the mean state and energy levels in the ocean's interior, on the other hand, is not common practice for ocean models. Since the model representation of deep turbulence is critical to the analysis presented in this study, it is key to assess the model capability to generate statistically realistic deep currents. Hence, in the following section, we assess model flow properties in the ocean interior vis-à-vis of relevant observationally-derived datasets. 


\section{Flow properties}

In this section we describe the characteristics of the simulated deep currents around the MAR and compare them to available observations. These charac-

teristics include the mean currents intensity and direction at $1500 \mathrm{~m}$ depth, the level of turbulence in the ocean interior below $1000 \mathrm{~m}$, and the time variability of bottom currents over the MAR and in the abyssal plain away from the MAR. We also compare the spatial characteristics of currents over the MAR to the currents in the open-ocean, far from topographic features.

\subsection{Mean currents}

The mean horizontal currents and temperature at $1500 \mathrm{~m}$ in ROMS6 (Figure 1) are compared to velocities derived from Argo floats displacements (ANDRO dataset at a horizontal resolution of $1^{\circ}$, Ollitrault and Rannou, 2013; Colin de Verdière and Ollitrault, 2016) and temperature from the World Ocean Atlas (WOA 2013 dataset, at a horizontal resolution of $1 / 4^{\circ}$, Locarnini et al., 2013; Zweng et al., 2013). Overall, the geographical mean and standard deviation of the different fields in the ROMSO.75 domain compare well in the model and in the observational data $\left(5.1 \pm 0.7\right.$ vs $5.0 \pm 0.6{ }^{\circ} \mathrm{C}$ for the temperature, $-0.5 \pm 1.5 \mathrm{vs}-0.3 \pm 0.8 \mathrm{~cm} \mathrm{~s}^{-1}$ for the zonal velocity, and $0.0 \pm 1.5 \mathrm{vs}$ $155-0.3 \pm 0.7 \mathrm{~cm} \mathrm{~s}^{-1}$ for the zonal and meridional velocity). Notice that a higher variability of velocity is expected in the model as the ANDRO dataset has a much lower resolution. The temperature structure is similar in models and observations. Specifically, the zonal gradient of the subtropical gyre and the meridional gradient over the MAR have the right amplitudes. Mean currents intensity and direction are in good agreement close to the MAR. Noticeably, a southwestward flow hugs the MAR on its eastern side from $45^{\circ} \mathrm{N}$ down to $37^{\circ} \mathrm{N}$ and veers westward at the latter latitude, close to Lucky Strike. The path of the deep-reaching North Atlantic Current flowing eastward is visible in model and observations. Differences in standing meandering patterns position and amplitude in the northwest part of the domain might be due to different 
time-averaging windows and lengths (ANDRO takes into account 12 years of Argo float data whereas ROMS6 currents are averaged over 2 years only), as well as a non-uniform sampling of Argo floats in space and time. Elsewhere, mean currents are relatively weak in both model and observations.

\subsection{Turbulence in the ocean's interior}

A measure of interior turbulence is given by the Eddy Available Potential Energy (EAPE), which measures the available potential energy associated with the turbulent part of the currents (Roullet et al., 2014). It is an analog of EKE that mainly encodes balanced motions such as mesoscale eddies. Global EAPE maps have been computed from the Argo floats dataset by Roullet et al. (2014) to provide ocean modelers with a reference product to assess the energetics of numerical simulations in the ocean's interior. The original product described in Roullet et al. (2014) has been slightly updated by (i) replacing virtual density by potential density ${ }^{3}$ and (ii) including more recent data up to July 2015 .

A basin-scale view of EAPE at $1000 \mathrm{~m}$ from the model and Argo floats data is shown in Figure 2. Levels of EAPE exhibit a strong zonal contrast. In the western subtropical gyre, the Gulf Stream has a strong imprint on EAPE at $1000 \mathrm{~m}$, with similar amplitudes in the model and data $\left(>1000 \mathrm{~cm}^{2} \mathrm{~s}^{-2}\right)$. It reveals a strong turbulent activity, with currents exceeding $40 \mathrm{~cm} \mathrm{~s}^{-1}$ (assuming that EAPE can be converted to $\mathrm{EKE}=\frac{1}{2} u_{R M S}^{2}$ ). There are also local maxima along the path of the North Atlantic Current. In the center and eastern part of the gyre, EAPE is strongly reduced $\left(<200 \mathrm{~cm}^{2} \mathrm{~s}^{-2}\right)$, as expected for more quiescent environments.

The vertical structure of EAPE has been averaged over two different areas : one in the mid-gyre above the MAR (around the Lucky Strike site) and another in the western subtropical gyre along the Gulf Stream (Figure 2c). The model reproduces fairly well the vertical distribution of EAPE, noticeably with a deep

\footnotetext{
${ }^{3}$ Both virtual and potential densities intend to remove pressure-induced compressibility; the former, less familiar, is mostly used in modelling contexts.
} 


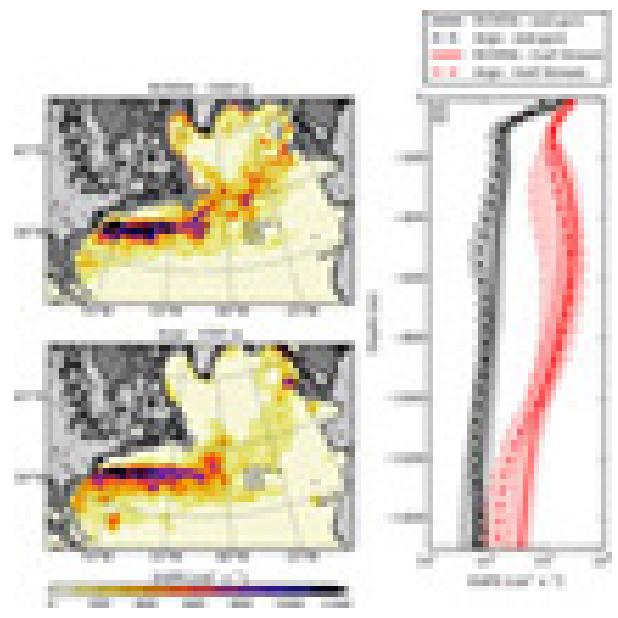

Figure 2: EAPE maps at $1000 \mathrm{~m}$ computed from (a) ROMS6 simulation and (b) Argo floats (Roullet et al., 2014). (c) Vertical profiles of EAPE spatially averaged on $4^{\circ} \times 4^{\circ}$ boxes shown in panels (a,b). Solid (dashed) lines are for ROMS6 (Argo) and black (red) lines are for the mid-gyre (Gulf Stream) box, each mean is surrounded by the standard deviations within the boxes. Black star is the Lucky Strike site.

maximum in the Gulf Stream area and a monotonic decrease of EAPE with depth in the mid-gyre area. Throughout the whole water column, EAPE in the mid-gyre is one order of magnitude smaller than in the Gulf Stream area. This confirms that Lucky Strike sits in a rather quiescent environment with modest levels of mesoscale turbulence. Overall, the model generates adequate levels of EAPE throughout the whole water column and spatial heterogeneities are well represented. Simulated eddying currents are thus statistically realistic.

3.3. Time variability of the currents

The tidal forcing in ROMS0.75T is purely barotropic, i.e., it includes only tidal sea surface height and barotropic currents at the domain boundaries. Hence, the model does not include internal tides generated outside the domain, but only the internal tides generated locally. Internal tides are generated mostly by tidal current interaction with topography (e.g., Merrifield and Holloway, 2002, in a similar primitive-equation hydrostatic model), and the domain 


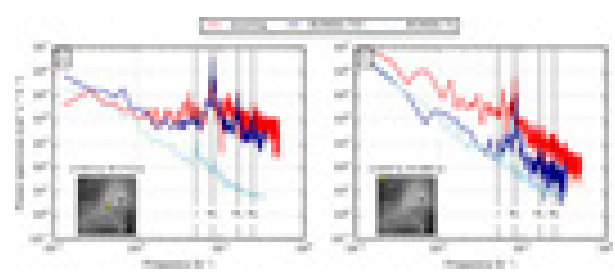

Figure 3: Power spectra of horizontal velocity for (a) on-ridge and (b) off-ridge moorings (red line) and the closest points in ROMS0.75T and ROMS0.75 to the moorings (dark and light blue respectively). Vertical black lines indicate the inertial frequency $f$, the $\mathrm{M}_{2}$-tide frequency and subsequent harmonics $\left(\mathrm{M}_{4}=2 \times \mathrm{M}_{2}\right.$ and $\left.\mathrm{M}_{6}=3 \times \mathrm{M}_{2}\right)$. Location of moorings are shown in yellow dots in inset maps (notice that the off-ridge point in the model is more than 100 grid points away from the northern and western boundaries so is not in the sponge layer). Data and seafloor depths ( $\mathrm{z}$ and $\mathrm{H}$, respectively) are indicated above inset maps. The on-ridge mooring $\left(37.29^{\circ} \mathrm{N}, 32.27^{\circ} \mathrm{W}\right)$ is at the Lucky Strike site and has been deployed by Ifremer, France (data available at http://www.ifremer.fr/sismerData/jsp/donneesInSitu.jsp). The off-ridge mooring $\left(43.30^{\circ} \mathrm{N}, 40.15^{\circ} \mathrm{W}\right)$ has been deployed by Fisheries And Ocean Canada (FAOC, data available on request at http://www.bio.gc.ca/science/data-donnees/base/index-en.php). We accessed these data throughout the Global Multi-Archive Current Meter Database (GMACMD, Scott et al., 2010; Scott and Furnival, 2013).

includes most of the MAR so that it is safe to assume that most of the internaltide field is generated within the model domain.

To assess the model capability to generate realistic internal waves, we compare time spectra of horizontal currents derived from moored current meters to their respective closest grid point in ROMS0.75 and ROMS0.75T (Figure 3). Mooring data are accessed via the Global Multi-Archive Current Meter Database (GMACMD, Scott et al., 2010; Scott and Furnival, 2013). Two current meters are selected; an on-ridge mooring, right at the location of the Lucky Strike vent $\left(37.29^{\circ} \mathrm{N}, 32.27^{\circ} \mathrm{W}\right.$, Figure 3a-inset) and an off-ridge mooring in the northwest abyssal plain $\left(43.30^{\circ} \mathrm{N}, 40.15^{\circ} \mathrm{W}\right.$, Figure 3 b-inset). Current meter depths (1615 $\mathrm{m}$ and $4325 \mathrm{~m}$, resp.) are relatively close to the seafloor (1713 m and $4865 \mathrm{~m}$, resp.), where internal tides - if any - are generated.

The on-ridge velocity power spectra show qualitatively good agreement between the mooring and ROMS0.75T (Figure 3a). $\mathrm{M}_{2}$ tides largely dominate 
the signals and their peaks have the same amplitude in ROMS0.75T and in the observations. Subsequent maxima around $\mathrm{M}_{2}$ harmonics $\left(\mathrm{M}_{4}=2 \times \mathrm{M}_{2}\right.$ and $\mathrm{M}_{6}=3 \times \mathrm{M}_{2}$ ) are also consistent. The rest of the super-inertial wave band is slightly lower in the simulation than in the mooring data. This is due to the model inability to simulate high-shear internal waves and turbulent processes down to mixing scales.

The off-ridge velocity power spectra are also dominated by $\mathrm{M}_{2}$ but show less energy in the whole internal waveband and a steeper spectral slope than their on-ridge counterparts (Figure 3b). This is expected since internal tide generation in the subtropical North Atlantic ocean occurs mostly over the MAR (see Green and Nycander, 2013, for estimates of energy conversion). Internal tide intensification close to the MAR is illustrated by the variance of vertical velocity close to the bottom (Figure $4 \mathrm{f}$ vs Figure 4d). Off the ridge, internal tides are not likely to be generated, due to weak barotropic tidal currents and smoother topography - the variance of vertical velocity in the vicinity of the offridge mooring location is similar in ROMS0.75 and ROMS0.75T (Figure 4). The off-ridge velocity power spectra show a weaker variability in the model than in the observations at all scales (Figure 3b). The difference at super-inertial scales might be related to a lack of remotely generated internal waves.

240 To identify the variability that can be attributed to tidal currents, we compare the spectra from the simulation with and without tides. The off-ridge spectra are similar in the sub-inertial wave band. As expected the ROMS0.75 spectra show no peak at $\mathrm{M}_{2}$ and a slight reduction of energy for frequencies larger than $\mathrm{M}_{2}$. Differences between the two are much greater on-ridge. The spectra diverge at frequencies higher than $10^{-2} \mathrm{~h}^{-1}$ (4 days), and there is a two order-of-magnitude difference in the super-inertial wave band. This suggests that at time scales smaller than $\sim 4$ days, the dynamics is strongly impacted by tidal currents and internal tides.

Investigating the life cycle of internal tides in the model is beyond the scope 250 of the present study. Nonetheless, modeled and current meter derived internal wave spectral slopes and peaks compare favorably, which supports decent wave 

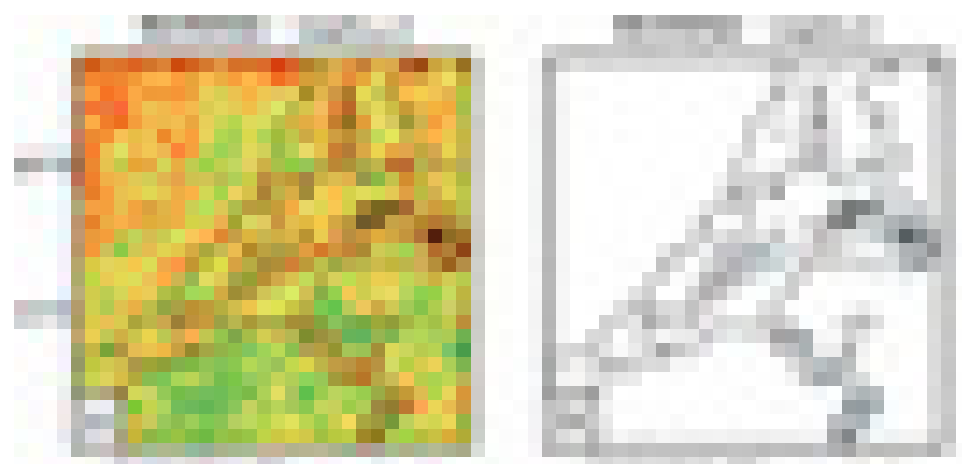

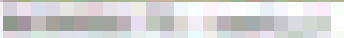

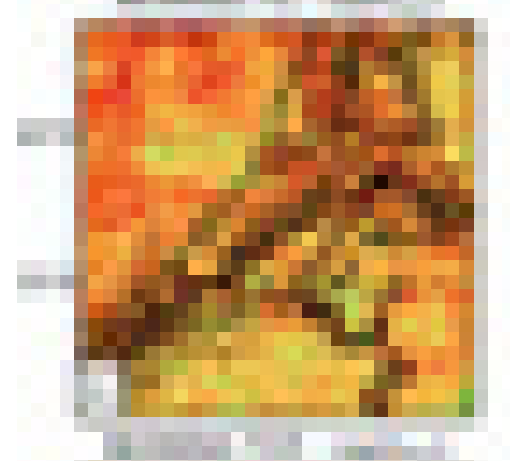

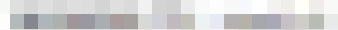
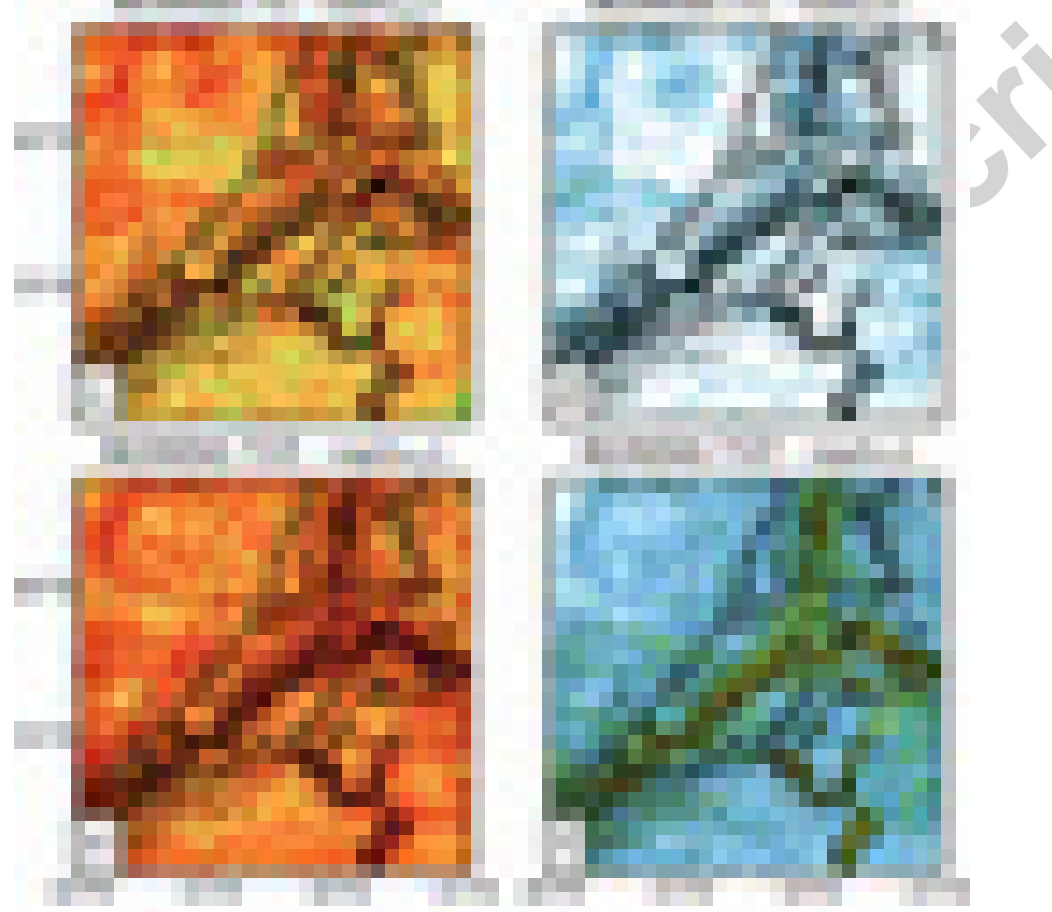

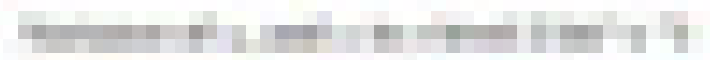

1

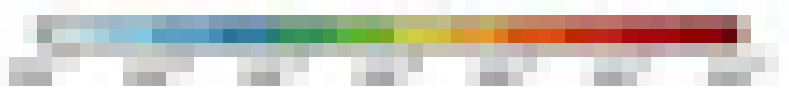

Figure 4: Variance of the horizontal velocity $u_{h}$ (left column) and vertical velocity $w$ (right column) in ROMS6 (top row), ROMS0.75 (middle row) and ROMS0.75T (bottom row) in the second sigma level from the bottom. Black lines are the 1000, 2000 and 3000-m bathymetry contours. 


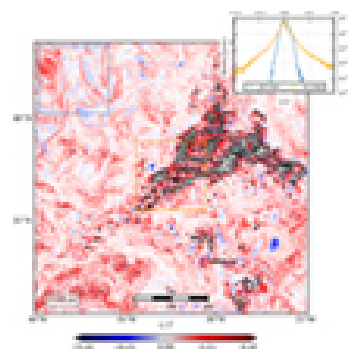

Figure 5: Snapshot of relative vorticity $\zeta$ non-dimensionalized by the local Coriolis frequency $f$ at $1500 \mathrm{~m}$ in ROMS0.75. Notice that the color bar does not fully span the field range. The inset shows the probability density function of $\zeta / f$ for the (blue line) off-ridge field and (orange) on-ridge field. Areas delimiting those fields are shown in the vorticity map with corresponding colors.

generation by the model.

\subsection{Spatial characteristics of the currents}

The spatial characteristics of the meso- and submesoscale turbulence are illustrated by a snapshot of relative vorticity at $1500 \mathrm{~m}$ for the ROMS0.75 simulation (Figure 5). The relative vorticity $\zeta=\partial_{x} v-\partial_{y} u$, where $(u, v)$ are the $(x, y)$ components of the horizontal flow, is normalized by the local Coriolis frequency $f$. This snapshot is typical of the turbulent states generated by the model. One can visually identify two different regions depending on the range of vorticity amplitude and spatial scales of coherent structures (eddies and fronts) :

- the off-ridge regime : northwest of the domain, relatively far from the MAR, vortical structures are dominated by the mesoscales. They have typical scales of several times the first baroclinic Rossby radius of deformation $R_{d}$ ( $R_{d} \sim 30 \mathrm{~km}$ in the area). The Rossby number $|\zeta / f|$ rarely exceeds 0.2 (see the probability density function of $\zeta / f$ in Figure 5-inset), indicating that the flow is close to geostrophy.

- the on-ridge regime : over the MAR, vortical structures are much smaller $\left(\leq R_{d}\right)$. Their amplitude is greater than in the off-ridge region and $|\zeta / f|$ exceeds 0.5 over $\sim 0.1 \%$ of the area (see inset in Figure 5 ). This indicates 


\footnotetext{
${ }^{4}$ Regressions are computed for $1 / \lambda$ in the range $1 / 200 \mathrm{~km}^{-1}-1 /(8 \delta x)=1 / 6 \mathrm{~km}^{-1}$ (gray shaded area in Figure 6). $8 \delta x$ is often considered as the upper limit of the dissipative range of the 3rd-order upstream-biased advection scheme used in the model. 95\% confidence intervals are 0.06 and 0.07 for the on-ridge and off-ridge regions, respectively.
} 


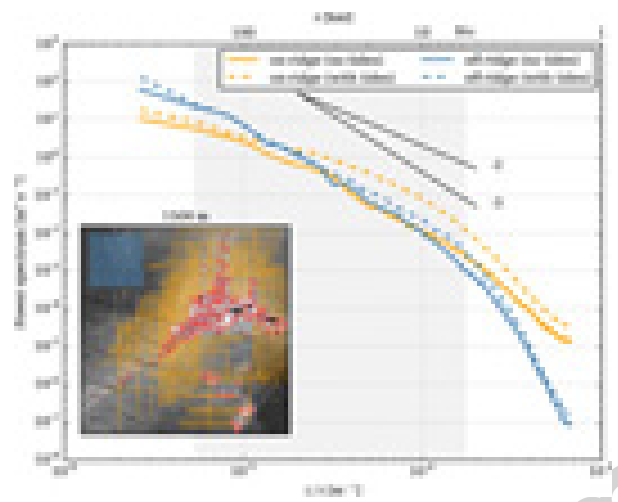

Figure 6: Horizontal velocity power spectra $E$ at $1500 \mathrm{~m}$ in ROMS0.75 (no tides) and ROMS0.75T (with tides). Solid (dashed) lines are for the simulation without (with) tides. Blue (orange) lines are for the off-ridge (on-ridge) areas. Spectra are computed for the crosssegment velocities (see segments in inset map) and averaged on 10 days. The gray shaded area is the spectral space in which power regressions $E \propto k^{-\alpha}$ are computed $(k=2 \pi / \lambda)$. Without tides, $\alpha_{\text {off-ridge }}=3.0$ and $\alpha_{\text {on-ridge }}=2.4$. For indication, $k^{-2}$ and $k^{-3}$ are shown in black lines. In the inset map, blue segments are chosen to be in the open ocean whereas orange segments intersect the oucropping topography at $1500 \mathrm{~m}$ (red contour). All segments have a length of $400 \mathrm{~km}$, which allow spectra to span more than two orders of magnitude of spatial scales (the Nyquist wavelength is $2 \times \delta x \sim 1.5 \mathrm{~km}$ ). 
theory holds at scales greater than $R_{d}$ and for $O(0.1)$ Rossby numbers, as observed off-ridge. In contrast, the on-ridge regime $\left(E \propto k^{-2.4}\right)$ departs from interior quasi-geostrophy. It is closer to modeled (Klein et al., 2008) and observed (Shcherbina et al., 2013) surface (within the mixed layer) submesoscale turbulent fields whose kinetic energy spectral shapes often vary in $k^{-2}$. As such, we suggest that the MAR, throughout frictional interactions with the flow, is a source of submesoscale turbulence.

A direct consequence of adding tides to the simulation is to increase kinetic energy levels at all wavenumbers on and off the ridge (Figure 6). This is the signature of internal tides generated on the ridge and propagating away.

\section{Lagrangian dispersion}

The fate of Lucky Strike vent effluents and larvae is examined using an offline Lagrangian advection code (section 2). Our analysis has two main foci, the impact of model resolution (meso- to submesoscale resolving) on dispersion and the impact of tides on dispersion. Therefore, particles are released in three different simulations, ROMS6 ( $\delta x=6 \mathrm{~km}$, no tides), ROMS0.75 ( $\delta x=0.75 \mathrm{~km}$, no tides) and ROMS0.75T ( $\delta x=0.75 \mathrm{~km}$, with tides). The setup of Lagrangian experiments is described in section 4.1. In section 4.2, we consider the absolute dispersion of particles whereas in section 4.3, we consider the separation statistics of particle pair trajectories.

\subsection{Setup}

The strong convection that occurs at hydrothermal vents creates buoyant plumes that extend vertically over hundreds of meters (e.g., Speer and Marshall, 1995). The plumes disperse vent effluents vertically, and the nearby larvae are entrained into the plume (Jackson et al., 2010). Hydrostatic models such as ROMS do not resolve convective plume dynamics. As such, we spread neutrally buoyant particles over a height extending from the seafloor $(z \sim-1800 \mathrm{~m})$ to $z \sim-600 \mathrm{~m}$ (Figure 7 ) as if they were between the vent and the neutrally 

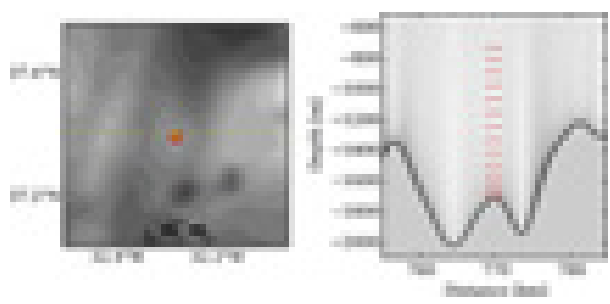

Figure 7: Initial location of particles (red dots) in (left) a horizontal plane and (right) in a vertical section, following the dashed yellow line in the left panel. In the left panel, topography is shaded gray with $\mathrm{CI}=100 \mathrm{~m}$ and the yellow dot is the position of the Lucky Strike site. In the right panel, grey lines represent the sigma levels and the distance is taken with respect to the western boundary of the domain.

buoyant plume, and even higher (e.g., see Figure 1 in Speer and Marshall,

1995). Vertically, particles are spread every two $\sigma$-levels on 14 levels. Horizontally, they are spread over a $2.25 \times 2.25-\mathrm{km}^{2}$ region, corresponding to a $3 \times 3$ ROMS0.75-grid-cell square (Figure 7). In the case of the Lagrangian experiment using ROMS6, particles are interpolated on the ROMS6 grid so that the setup is exactly the same as in ROMS0.75 and ROMS0.75T experiments. Overall, 126 particles are released every $6 \mathrm{~h}$ for 10 months in ROMS0.75(T) - due to computational limitations - and for 18 months in ROMS6. Statistics are derived on more than 150000 particles in each simulation.

In the following, we focus on particles released below $1400 \mathrm{~m}$, which are the most relevant for connectivity purposes addressed in section 5 . The reader interested in the sensitivity of the dispersion to particles' initial depth - relevant to the fate of vent effluents - is referred to Appendix A.

\subsection{Absolute dispersion}

In the following, we adopt Poje et al. (2010)'s notations. Particle trajectory is denoted by $\boldsymbol{x}(\boldsymbol{a}, t)$ where the particle label $\boldsymbol{a}=\boldsymbol{x}\left(\boldsymbol{a}, t_{0}\right)$ is given by its initial position. The horizontal and vertical absolute dispersion are defined as

$$
A_{h}^{2}(t)=\left\langle\left(\boldsymbol{x}_{\boldsymbol{h}}(\boldsymbol{a}, t)-\boldsymbol{a}_{\boldsymbol{h}}\right)^{2}\right\rangle \text { and } A_{v}^{2}(t)=\left\langle\left(\boldsymbol{x}_{\boldsymbol{v}}(\boldsymbol{a}, t)-\boldsymbol{a}_{\boldsymbol{v}}\right)^{2}\right\rangle \text {, }
$$




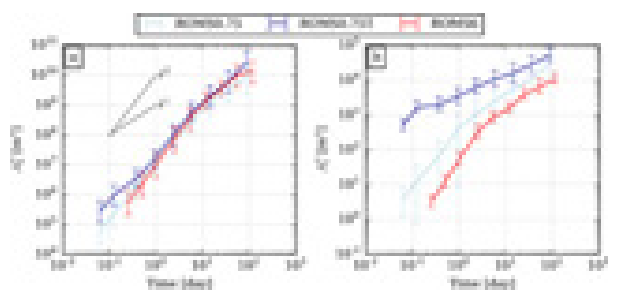

Figure 8: (a) Horizontal and (b) vertical absolute dispersion for (light blue lines) ROMS0.75, (dark blue lines) ROMS0.75T and (red lines) ROMS6. Particles were released deeper than $1400 \mathrm{~m}$. Error bars are standard deviations from the mean.

where $\boldsymbol{x}_{\boldsymbol{h}}=\boldsymbol{x} \cdot(1,1,0)^{T}$ and $\boldsymbol{x}_{\boldsymbol{v}}=\boldsymbol{x} \cdot(0,0,1)^{T}$ (same notation for $\boldsymbol{a}$ ), and $\langle\cdot\rangle$ denotes the average over all particle pairs.

The horizontal absolute dispersion $A_{h}^{2}$ is much higher in ROMS0.75T than in ROMS0.75 and ROMS6 in the first stage, between the particle release and 1 day (Figure 8a). It underlines the role of the tidal currents in rapidly spreading particles away from their release site. At larger time scales, between 1 day and $\sim 10$ days, particles experience a very similar horizontal dispersion in the three simulations, and $A_{h}^{2}$ follows a ballistic regime $-A_{h}^{2}(t) \propto t^{2}$-, as predicted by the theory for homogeneous and stationary turbulent flows (Taylor, 1921). This similarity between the experiments confirms the non-locality of the absolute dispersion, i.e., it is controlled by mesoscale motions. Submesoscales do not come into play to modify the absolute dispersion. At time scales longer than $\sim 10$ days, the horizontal absolute dispersion slows down at a similar pace (within the error bars) for the three simulations. Theoretically, $A_{h}^{2}$ should tend towards a Brownian regime $-A_{h}^{2}(t) \propto t$, which is qualitatively close to the modelled regimes.

The vertical absolute dispersion $A_{v}^{2}$ is significantly increased by the submesoscale and tidal currents (Figure $8 \mathrm{~b}$ ), as supported by the enhanced variance of vertical velocity (Figures 4d,f). Differences are particularly intensified at the short time scales - $O(1)$ day -, before the mesoscales come into play to drive the non-local absolute dispersion. Quantitatively, after 10 days, particles have on average experienced a vertical motion of $40 \mathrm{~m}$ in ROMS6, $60 \mathrm{~m}$ in ROMS0.75, 
and $120 \mathrm{~m}$ in ROMS0.75T.

\subsection{Relative dispersion}

The relative separation of a particle pair $\left(\boldsymbol{a}_{\mathbf{1}}, \boldsymbol{a}_{\mathbf{2}}\right)$ is

$$
\begin{aligned}
\boldsymbol{D}\left(t, \boldsymbol{D}_{\mathbf{0}}\right) & =\boldsymbol{D}_{\mathbf{0}}+\left(\boldsymbol{x}\left(\boldsymbol{a}_{\mathbf{1}}, t\right)-\boldsymbol{x}\left(\boldsymbol{a}_{\mathbf{2}}, t\right)\right) \\
& =\boldsymbol{D}_{\mathbf{0}}+\int_{t_{0}}^{t} \Delta \boldsymbol{v}\left(t^{\prime}, \boldsymbol{D}_{\mathbf{0}}\right) \mathrm{d} t^{\prime},
\end{aligned}
$$

with $\boldsymbol{D}_{\mathbf{0}}=\boldsymbol{a}_{\mathbf{1}}-\boldsymbol{a}_{\mathbf{2}}$ the initial distance and $\Delta \boldsymbol{v}=\left(\boldsymbol{v}\left(\boldsymbol{a}_{\mathbf{1}}, t\right)-\boldsymbol{v}\left(\boldsymbol{a}_{\mathbf{2}}, t\right)\right)$ the Lagrangian velocity difference. By averaging over particles pairs $(\langle\cdot\rangle)$ we form the horizontal and vertical relative dispersions

$$
D_{h}^{2}(t)=\left\langle\boldsymbol{D}_{\boldsymbol{h}}(t) \cdot \boldsymbol{D}_{\boldsymbol{h}}(t)\right\rangle \text { and } D_{v}^{2}(t)=\left\langle\boldsymbol{D}_{\boldsymbol{v}}(t) \cdot \boldsymbol{D}_{\boldsymbol{v}}(t)\right\rangle \text {. }
$$

Horizontal and vertical relative diffusivity can be derived from these quantities (LaCasce, 2008) as

$$
\kappa_{h}=\frac{1}{2} \frac{\mathrm{d}}{\mathrm{d} t} D_{h}^{2} \text { and } \kappa_{v}=\frac{1}{2} \frac{\mathrm{d}}{\mathrm{d} t} D_{v}^{2} .
$$

The scale dependence of the relative dispersion at a given length scale $r$ is measured by the separation velocity $\Delta v(r)=\left(\delta v(r)_{\mathrm{rms}}\right)$, with $\delta v(r)=(\boldsymbol{v}(\boldsymbol{x}+$ $\boldsymbol{r})-\boldsymbol{v}(\boldsymbol{x})) \cdot \boldsymbol{r} /\|\boldsymbol{r}\|$ and where the average is done on pairs separated by distance $r$ (Poje et al., 2014). $\Delta v(r) / r$ is homogeneous to an inverse time scale and characterizes how fast particle separate at a given length scale.

An alternative scale-dependent variable to quantify dispersion is the FiniteSize-Lyapunov-Exponent (FSLE, Aurell et al., 1997). It is defined as

$$
\lambda(\delta)=\frac{\ln (\alpha)}{\langle\tau(\delta)\rangle},
$$

where $\langle\tau(\delta)\rangle$ is the average time over which particle pairs have been separated from $\delta$ to $\alpha \delta$ ( $\alpha>1$ is a constant parameter). Following Poje et al. (2010) and Bracco et al. (2016), we chose $\alpha=1.2$.

In the following, we present pair statistics computed for pairs of particles initially distant by less than $1 \mathrm{~km}$ in the horizontal and $15 \mathrm{~m}$ in the vertical. 

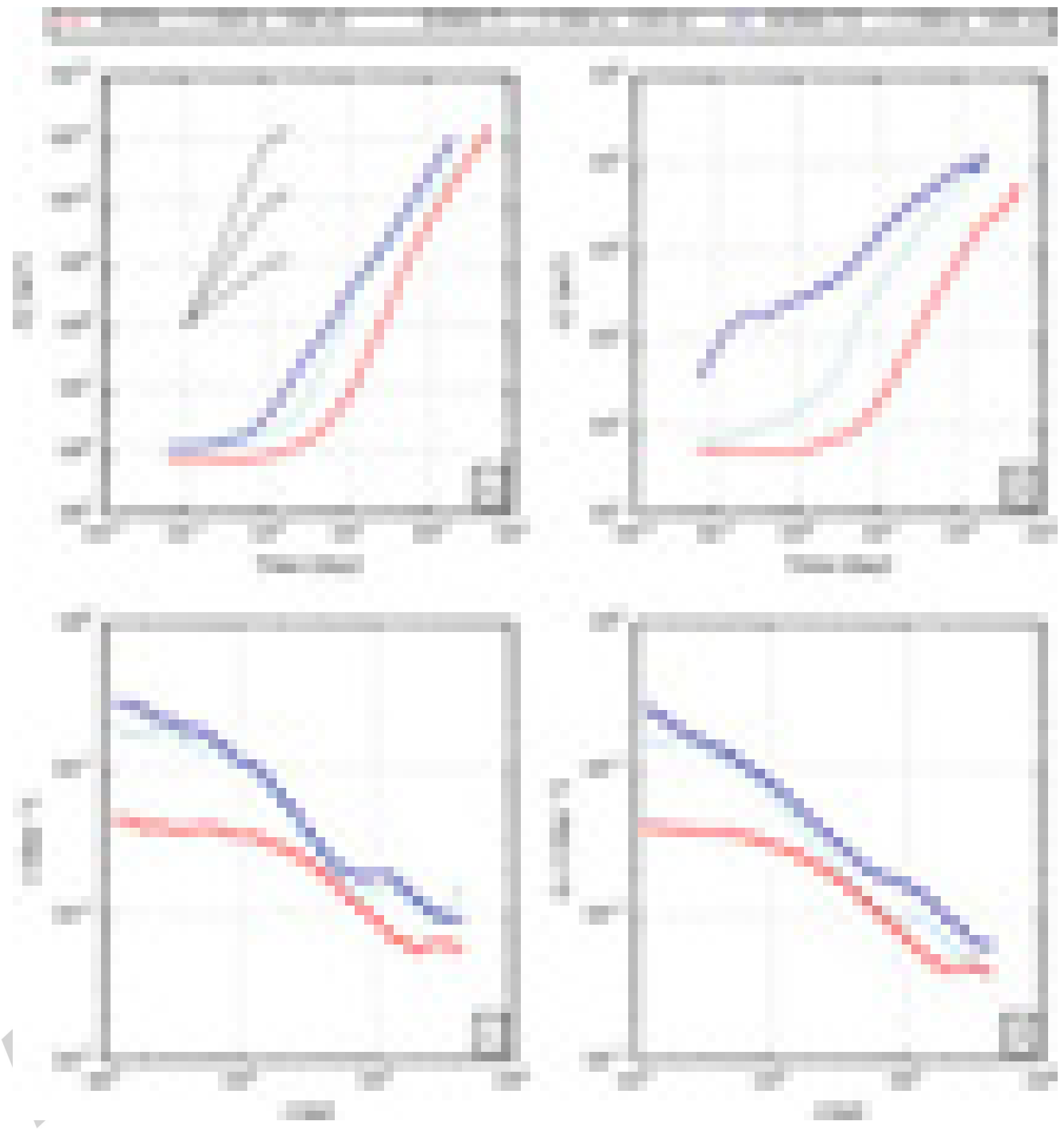

Figure 9: Pair statistics in ROMS6 (red lines), ROMS0.75 (light blue lines) and ROMS0.75T (dark blue lines) for particles with initial position deeper than $1400 \mathrm{~m}$. (a) horizontal dispersion $D_{h}^{2}$ (Eq. 3), (b) vertical dispersion $D_{v}^{2}$ (Eq. 3), (c) Finite Size Lyapunov Exponents $\lambda$ (Eq. 5) and (d) separation speed scaled by relative distance $\Delta v / \delta$. 


\subsubsection{Impact of submesoscale flows}

Statistics for pairs of particles released in ROMS6, ROMS0.75 and ROMS0.75T between 1400 and 1000-m depth are shown in Figure 9. Relative horizontal dispersion $D_{h}^{2}$ follows three stages in ROMS0.75 and ROMS0.75T (Figure 9a).

In the first stage, from the release to approximately 5 days, $D_{h}^{2}$ grows exponentially with time up to an equivalent length scale of $\left(D_{h}^{2}(t=5 \text { days })\right)^{1 / 2} \sim 5-$ $10 \mathrm{~km}$. Theory relates such a regime with the enstrophy cascade regime of two-dimensional forced turbulence (LaCasce, 2008). This regime typically occurs at spatial scales smaller than the deformation radius and at short time scales, which is consistent with our finding. For instance, it was observed in the Gulf of Mexico for the first $\sim 10$ days and $D_{h}<40-50 \mathrm{~km}$ (LaCasce and Ohlmann, 2003), and in the eastern North Atlantic for the first 20 days and $D_{h}<25 \mathrm{~km}$ (Ollitrault et al., 2005).

385 In the second stage, from 5 to approximately 60 days, $D_{h}^{2}$ follows a powerlaw regime $D_{h}^{2}(t) \propto t^{\beta}$, with $2<\beta<3(\beta=3$ corresponds to the famous Richardson's regime, Richardson, 1926). Between 5-60 days, $\beta=2.5$ both in ROMS0.75 and ROMS0.75T. In statistically stationary and homogeneous $2 \mathrm{D}$ turbulence theory, $\beta$ is linked to the slope of the Eulerian kinetic energy spectrum (Poje et al., 2010). It is still debated whether this theory applies or not in more complex oceanic flows where stratification, rotation, 3D non-isotropic currents and boundaries are present (e.g., discussion in Haza et al., 2008). Nonetheless, this power-law regime indicates that dispersion is dominated by local scales of motions, i.e., submesoscales.

In the third stage, at times greater than 60 days, dispersion is slowed down. At long time scales, pair velocities are no longer correlated and dispersion tends towards $D_{h}^{2} \propto t$ (Taylor's regime, or random walk dispersion, Taylor, 1921). This regime is rarely observed in the ocean but has been simulated (Poje et al., 2010).

The dispersion in ROMS6 exhibits a qualitatively similar behaviour with the same three stages but it differs quantitatively. The growth of $D_{h}^{2}(t)$ is signif- 
icantly delayed compared to that in ROMS0.75(T) (Figure 9a). The vertical dispersion is strongly reduced, especially at times shorter that 10 days. After 10 days, on average, particles are vertically spread apart by $14 \mathrm{~m}$ in ROMS6 vs $70 \mathrm{~m}$ in ROMS0.75. Bracco et al. (2016) find a more modest increase in deep vertical dispersion between simulations at $5-\mathrm{km}$ and $1.6-\mathrm{km}$ resolutions (45 $\mathrm{m}$ vs $63 \mathrm{~m}$ ). Also, Zhong and Bracco (2013) find a significant increase for near-surface (particles released at $100 \mathrm{~m}$ ) vertical dispersion between simulations at 5-km and 1-km resolutions (17 m vs $28 \mathrm{~m}$ ). During the power-law regime (10-100 days), the slope of $D_{h}^{2}$ is $\beta=2.6$ in ROMS6, which is similar to the higher resolution simulations $(\beta=2.5$ both in ROMS0.75 and ROMS0.75T). This similarity is consistent with the results of sensitivity experiments on horizontal resolution in Poje et al. (2010).

Statistics conditioned on the pair separation distance $\delta$ give complementary information on the scales of motion involved in the dispersion. In the $\delta=1-20-$ $\mathrm{km}$ range, FSLE $\lambda(\delta)$ (Figure 9c) and $\Delta v(\delta) / \delta$ (Figure 9d) are almost constant in ROMS6. This invariant regime is expected since no dynamical structure smaller than $20 \mathrm{~km}$ (i.e., several times the model resolution) participates to Lagrangian stirring. In contrast, in ROMS0.75(T), monotonically decreasing ${ }_{420} \lambda(\delta)$ and $\Delta v(\delta) / \delta$ for $\delta=1-20 \mathrm{~km}$ indicate that dispersion is driven by local processes, i.e., submesoscales. Similarly, Bracco et al. (2016) find that deep $(1500 \mathrm{~m})$ submesoscale currents in the Gulf of Mexico impact the dispersion at 10-40 km scales. A similar behaviour was demonstrated by Poje et al. (2014) at the surface in the Gulf of Mexico, monitoring pair dispersion by actual oceanic currents vs altimetry-derived currents.

Probability density functions (PDFs) of $D_{h}$ at long time scales reveal some pairs of very close particles in the three runs (not shown). To investigate the potential role of SCVs in trapping particles on long time scales, we isolated a subset of pairs of particles distant by less than $20 \mathrm{~km}$ at 90 days, and computed their spin parameter $\Omega$, following Veneziani et al. (2005),

$$
\Omega=\frac{u^{\prime} \mathrm{d} v^{\prime}-v^{\prime} \mathrm{d} u^{\prime}}{2 \Delta t K}
$$




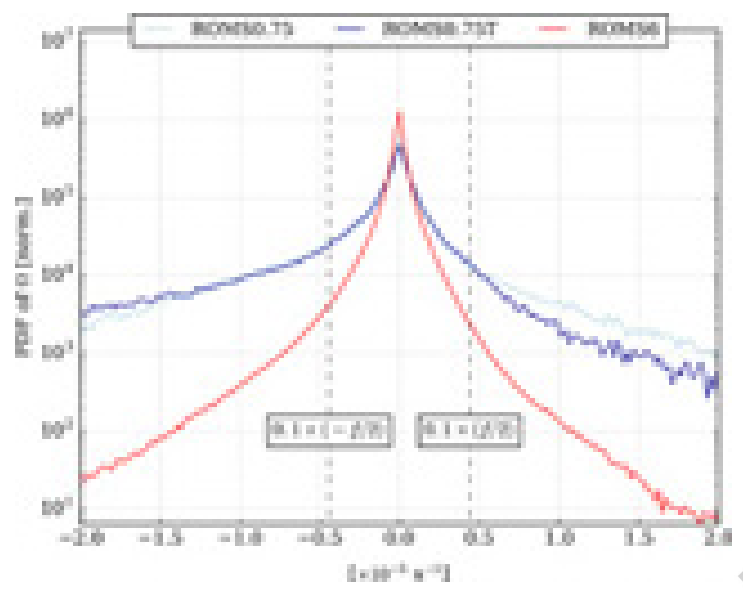

Figure 10: Probability density function of the spin parameter $\Omega$ in ROMS0.75 (light blue), ROMS0.75T (dark blue) and ROMS6 (red).

$\Omega$ is interpreted as the particle mean angular rotation during the time increment $\Delta t$ (Veneziani et al., 2005). In Eq. 6, $u^{\prime}$ and $v^{\prime}$ are the zonal and meridional velocity of the particles, low-passed filtered at 2 days to remove the tidal and near-inertial currents; $\mathrm{d} u^{\prime}$ and $\mathrm{d} v^{\prime}$ are the variations of $u^{\prime}$ and $v^{\prime}$ during $\Delta t$, and $K=\frac{1}{2}\left(\overline{u^{\prime 2}}+\overline{v^{\prime 2}}\right)$ is the EKE ( $\cdot$ denotes averaging over the subset of particles). In the three simulations, the PDF of $\Omega$ peaks at zero (Figure 10), which means that most of the particles are in non-looping structures (adopting the vocabulary in Veneziani et al., 2005). However, tails are much wider in ROMS0.75(T) as compared to ROMS6, which reveals that particles are embedded in looping structures - i.e., SCVs here, as the distance between particles in the subset is less than the deformation radius. Veneziani et al. (2005) demonstrated that $\Omega$ is related to the relative vorticity $\zeta$ as $\zeta \sim 2 \Omega$. To quantify the number of SCVs embedding pairs of particles, we integrate the PDFs for $|\Omega|>0.1 \times(f / 2)(f$ is the Coriolis parameter), which corresponds to $|\zeta|>0.1 \times f$, a low-estimate value of SCVs' typical vorticity (e.g., McWilliams, 1985). Boundaries for integration are shown as dashed lines in Figure 10. Overall, the contribution of SCVs in trapping long-lived pairs of particles is $21 \%$ in ROMS0.75 and $19 \%$ in ROMS0.75T. This contribution falls to $2 \%$ in ROMS6. This diagnostic quan- 
tifies the role of SCVs in trapping particles on long time and spatial scales, as revealed by a growing number of observations (Testor and Gascard, 2003; Reverdin et al., 2009; Bower et al., 2013; Bosse et al., 2015, 2016, 2017).

\subsubsection{Impact of tides}

The impact of tides on horizontal relative dispersion is insignificant (Figure 9a). This is confirmed by scale-dependent diagnostics that show similar behaviours in ROMS0.75 and ROMS0.75T (Figures 9c,d). There is no generation of tidal eddies in ROMS0.75T (e.g., Callendar et al., 2011, and references therein), which might have involved material transport, likewise on continental shelves (Geyer and Signell, 1992). ${ }^{5}$

In contrast, tidal currents and internal tides play a major role on the vertical relative dispersion of particles, as expected from the increased variance of vertical velocity over the MAR in ROMS0.75T (Figure 4). On average, after 1 day (10 days, resp.), two particles can be spread apart vertically by $40 \mathrm{~m}$ (140 m, resp.) in ROMS0.75T compared to $14 \mathrm{~m}$ (70 m, resp.) in ROMS0.75 (Figure $9 \mathrm{~b}$ ). This factor of 2-3 increase in vertical dispersion by the tides holds between the initial release time and $O(10)$ days.

Overall, tides yield an equivalent vertical eddy diffusivity of $\kappa_{v} \sim 1-8 \times$ $10^{-3} \mathrm{~m}^{2} \mathrm{~s}^{-1}$ (Eq. 4), significantly higher than in simulations without tides where $\kappa_{v} \sim 0.1-3 \times 10^{-3} \mathrm{~m}^{2} \mathrm{~s}^{-1}$ (Figure 9d). This enhancement of vertical diffusivity by tides is expected since tides are known to generate strong mixing over the rough topography of the MAR (e.g., Polzin et al., 1997). However, diffusivities diagnosed here are significantly larger than estimates from microstructure measurements or dye-release experiments over the flanks of the MAR in the South Atlantic $\left(\sim 10^{-4} \mathrm{~m}^{2} \mathrm{~s}^{-1}\right.$ in Polzin et al. (1997) and $2-4 \times 10^{-4} \mathrm{~m}^{2} \mathrm{~s}^{-1}$ in Ledwell et al. (2000)). A reason for this difference is that the latter measure-

\footnotetext{
${ }^{5}$ The reason is that tidal barotropic currents over the MAR are limited to $u_{M_{2}}=3-5 \mathrm{~cm} \mathrm{~s}^{-1}$, which makes a tidal excursion of $u_{M_{2}} / \omega_{M_{2}}<400 \mathrm{~m}\left(\omega_{M_{2}}\right.$ is the dominant semi-diurnal frequency), thus smaller than the model horizontal resolution.
} 
relative dispersion of particles is related to a wider range of processes, including adiabatic ones such as isopycnal heaving and isopycnal diffusivity. A similar difference is found in Bracco et al. (2016). Nonetheless, the recent work of Mashayek et al. (2017) reconciles microstructure-derived and tracer-derived estimates of diffusivity. They demonstrate that passive tracers accumulate around topographic structures featuring enhanced diffusivity, therefore augmenting the overall estimates of diffusivity.

\section{Discussion on the connectivity between hydrothermal vents}

In this section, we illustrate how model resolution and tidal currents impact the connectivity between hydrothermal vent sites in the deep ocean. To get an insight on the absolute dispersion by the mean currents solely, a fourth experiment is conducted using the time-mean currents of ROMS6 - average is done over the 2 years following the first year of dynamical spin-up. This simulation mimics the weak $\left(O(1) \mathrm{cm} \mathrm{s}^{-1}\right)$ deep laminar currents produced by non-mesoscale-resolving models such as climate models. The northern MAR hosts several hydrothermal vents associated with specific ecosystems (among the most studied ones, Menez Gwen, Lucky Strike, Saldanha ${ }^{6}$ and Rainbow locations are shown in Figure 11a-d). Population connectivity between vent sites has important implications for the dynamics of faunal communities at ecological time scales (i.e., a few generations time scale) and the persistence of endemic species at evolutionary time scales (Cowen and Sponaugle, 2009).

To connect with biological issues we identify the particles with larvae of a given taxa, Bathymodiolus mussels, one of the dominant organisms at many hydrothermal vents and cold seeps worldwide (Miyazaki et al., 2010). Connectivity results from dispersal that occurs primarily during the pelagic larval stage of species (Cowen and Sponaugle, 2009). This stage is characterized by its

\footnotetext{
${ }^{6}$ Saldanha's ecosystem differs from typical hydrothermal vent ecosystems though (Biscoito et al., 2006).
} 
pelagic larval duration (PLD), which depends on the species itself and on hydrological and physico-chemical properties such as temperature (O'Connor et al., 2007). Four species of Bathymodiolus inhabit vent sites on the MAR (Van Cosel et al., 1999; van der Heijden et al., 2012). PLDs of Bathymodiolus mussels vary from 3-4 months for the dominant species on the northern MAR Bathymodiolus azoricus (Colaço et al., 2006; Husson et al., 2016), to more than a year for Bathymodiolus childressi (Arellano and Young, 2009). As Bathymodiolus' eggs are slightly negatively buoyant (although not precisely quantified, Arellano and Young, 2009), they are not likely to spread upon release otherwise than through their entrainment in the rising vent plume, which extends $300-500 \mathrm{~m}$ above the source (Speer and Marshall, 1995; Wilson et al., 1996). Thus, we select only particles released deeper than $400 \mathrm{~m}$ above the source, i.e., deeper than $1400 \mathrm{~m}$.

In sections 5.1 and 5.2, we discuss the dispersion of larvae after 30 and 180 days, representative of small and long PLDs, respectively. In section 5.3, we focus on the impact of topography and tides on larvae dispersion.

\subsection{Dispersion at 30 days}

The probability density of particles after 30 days is shown in Figure 11 for ROMS0.75, ROMS0.75T, ROMS6 and an additional simulation that uses the time-mean currents of ROMS6.

The addition of mesoscale variability to the mean currents dramatically changes the distribution of particles (compare Figure 11a with Figure 11b). The effect of mesoscale eddies on dispersion is to spread particles away from the mean current, leading to a diffuse cloud of particles instead of a continuous

${ }_{520}$ line. Particles are mostly stirred by mesoscale structures $\left(O\left(R_{d}\right), R_{d} \sim 30 \mathrm{~km}\right)$, thus the cloud does not exhibit smaller scale patterns.

The Lucky Strike vent field lies deep inside a rift valley (see Thurnherr et al., 2008 , for a description of the hydrography). The mean current is northward at these depths, but the particles quickly fill the two parts of the rift valley north and south of the release site in ROMS6.

After 30 days, particles reach the nearby Menez Hom and almost reach the 

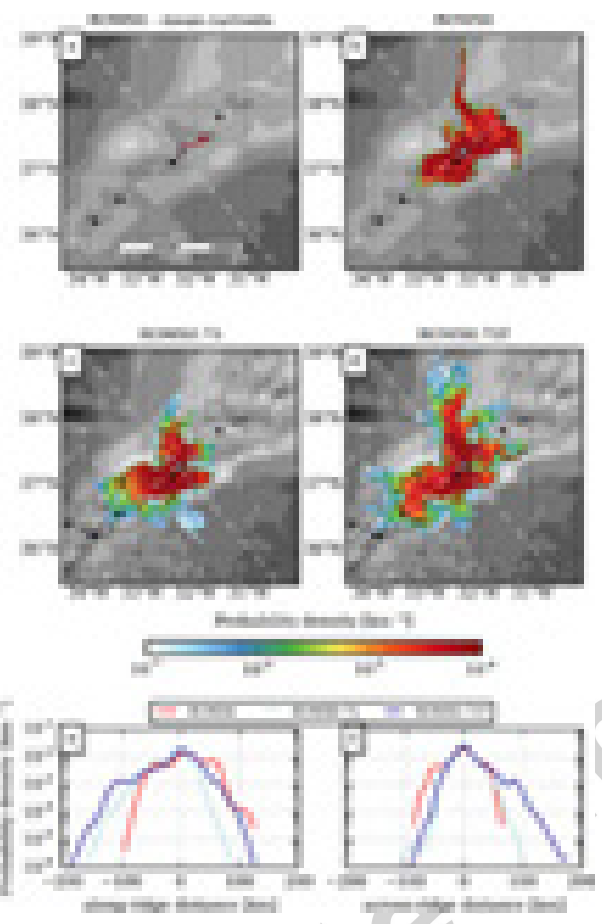

Figure 11: Probability density of particles at 30 days, in (a) ROMS6-mean currents (advection is performed using the mean currents - i.e., time invariant - in ROMS6), (b) ROMS6, (c) ROMS0.75 and (d) ROMS0.75T. Only particles released deeper than $1400 \mathrm{~m}$ are selected. Probability $P$ is normalized such as $\int_{\mathcal{D}} P \mathrm{~d} x \mathrm{~d} y=1$, where $\mathcal{D}$ is the area of the domain. The thin black line is the $5 \times 10^{-6}-\mathrm{km}^{-2}$ contour. The white star is the Lucky Strike site and black stars are the principal hydrothermal vents in the area according to the OSPAR Commission (document available at http://www.ospar.org/documents?v=7220), from northeast to southwest : Menez Gwen, Menez Hom, Saldanha and Rainbow. Background shades of gray is the model bathymetry with 500-m contour interval. (e) and (f) are the probability density in the along- and across-ridge directions, respectively, for ROMS6 (red), ROMS0.75 (light blue) and ROMS0.75T (dark blue). Directions are shown in white dashed lines on panels a-d. 
northernmost Menez Gwen site, but connectivity with other sites is unlikely in this simulation.

Adding submesoscale variability and tides does not impact the overall absolute dispersion. On average, particles are located at similar distances from the source in ROMS6 and ROMS0.75(T) (see the red area in Figure 11). However, it increases the relative diffusivity of the cloud of particles (Figure 11c,d). Indeed, the area covered by probability densities smaller than $5 \times 10^{-6} \mathrm{~km}^{-2}$ (thin black line in Figures 11a-d) is significantly increased compared to ROMS6 ${ }_{535}\left(3 \times 10^{3} \mathrm{~km}^{2}\right.$ in ROMS6 vs $12 \times 10^{3}$ and $21 \times 10^{3} \mathrm{~km}^{2}$ in ROMS0.75 and ROMS0.75T, respectively). As demonstrated in Section 4.3.1, local scales - i.e., submesoscales - increase the relative dispersion on the MAR. It results in an enhanced equivalent diffusivity of the cloud of particles at $O(1-10)$ days, which displays patterns of dispersion smaller than the deformation radius.

Connectivity with the southern Saldanha hydrothermal site becomes possible with the addition of submesoscale currents, and particles almost reach the southernmost Rainbow site when considering both submesoscale and tidal currents. However, particles still do not reach the Menez Gwen site, and appear to not extend as far as ROMS6 in the northeast direction.

${ }_{545}$ Indeed, we have to be cautious on drawing conclusions on the connectivity as mesoscale circulations are inherently different in ROMS6 and ROMS0.75(T), and the simulations are not long enough to get a statistically significant picture of mesoscale variability. The mesoscale variability could be responsible for moving more particles to the northeast in ROMS6, while moving more particles to the southwest in ROMS0.75(T). Therefore, we cannot conclude on the impact of submesoscale and tidal currents on connectivity. The mesoscale variability may allow for connecting different sites on interannual scales. However, mesoscale variability being equal, the addition of submesoscale and tidal currents should slightly improve the chances of reaching the different sites. 

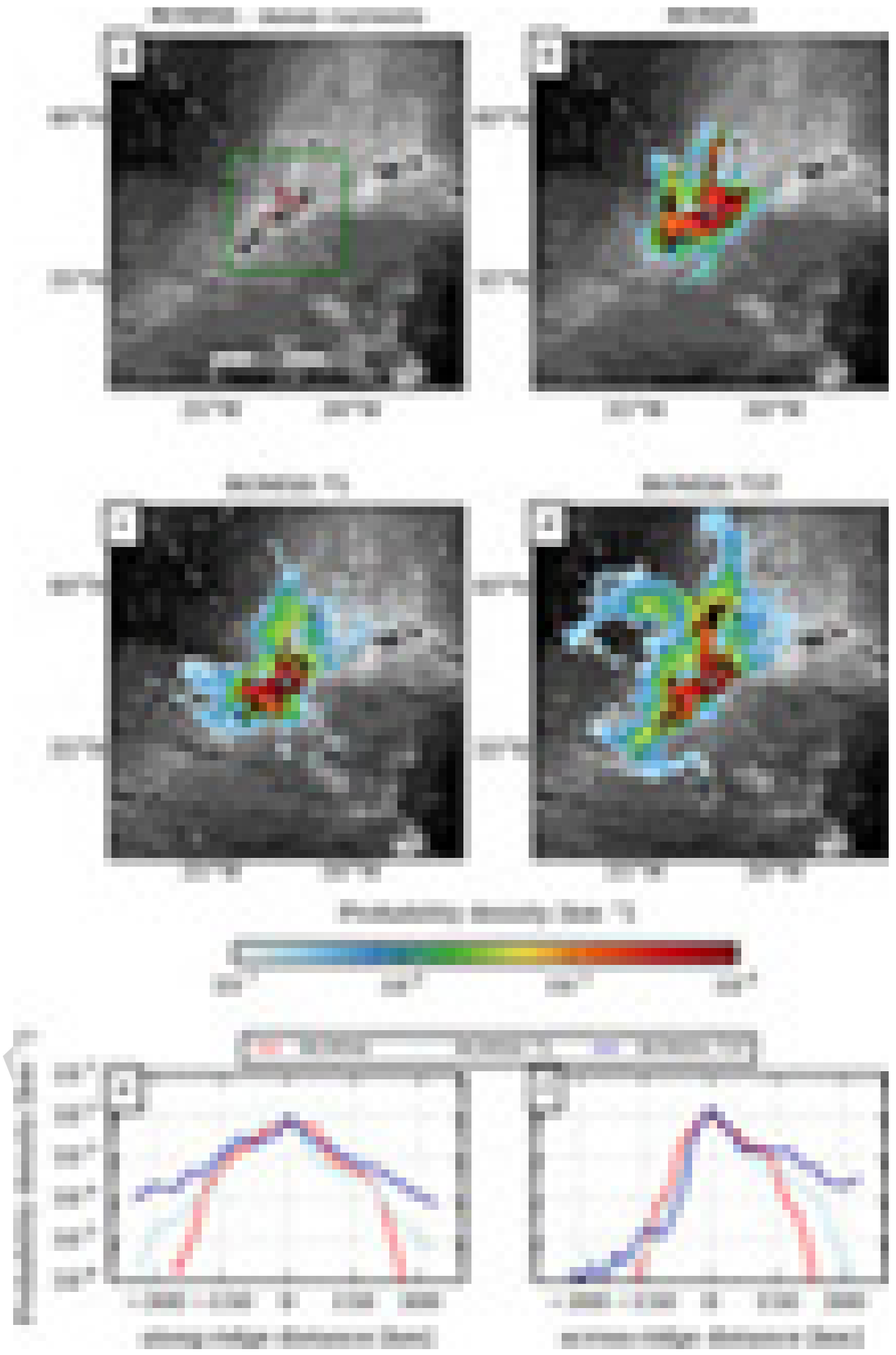

Figure 12: Same as Figure 11 at 180 days. The green box in (a) shows the map boundaries in Figures 11a-d. 


\subsection{Dispersion at 180 days}

Probability density at 180 days is shown in Figure 12. The southernmost site Rainbow and the northernmost site Menez Gwen are more likely to be reached in all simulations.

As previously, the absolute dispersion is not significantly impacted by the resolution, and again, care must be taken on an increased connectivity potential as mesoscale circulations are different in the three simulations. However, the increase of diffusivity for the cloud of particles with the addition of submesoscale currents and tides is more clearly visible. The area covered by probability densities larger than $1 \times 10^{-7} \mathrm{~km}^{-2}$ extends in all directions with the realism of the simulation.

Although not precisely quantified, reproductive studies indicate high fecundity in Bathymodiolus mussels (Tyler and Young, 1999). Considering their egg size and body length, Bathymodiolus fecundity can reasonably be assumed to be at least in the same order of magnitude as in coastal mytilids, which can release more than $10^{6}$ eggs/female/spawning season (Sprung, 1983). The average density of sexually mature mussels (i.e., exceeding $3 \mathrm{~cm}$ body length, Colaço et al., 2006) is $10^{3}$ ind $\mathrm{m}^{-2}$ (Cuvelier et al., 2011a; Husson et al., 2016), half of them being females. Estimating the surface covered by these mussels to be about $10 \mathrm{~m}^{2}$ in Eiffel Tower (Figure 3 in Cuvelier et al. (2009) and Cuvelier et al. (2011b)), we grossly estimate that 5000 mature females may spawn their eggs each season at this edifice. Assuming similar fecundities to that of coastal mytilids, we can reasonably assume that at least $10^{9}$ eggs are laid each year on the Eiffel Tower edifice solely. Rainbow vent field comprises more than 30 groups of active chimneys spread over $1.5 \times 10^{4} \mathrm{~m}^{2}$ (Desbruyères et al., 2000). Given

a probability of $10^{-5} \mathrm{~km}^{-2}$ for particles to reach Rainbow site (lower-bound estimate, Figure 12d), we estimate that at least 150 eggs can reach Rainbow edifices within the 6 months following the annual spawning.

\subsection{On the role of topography and tides}




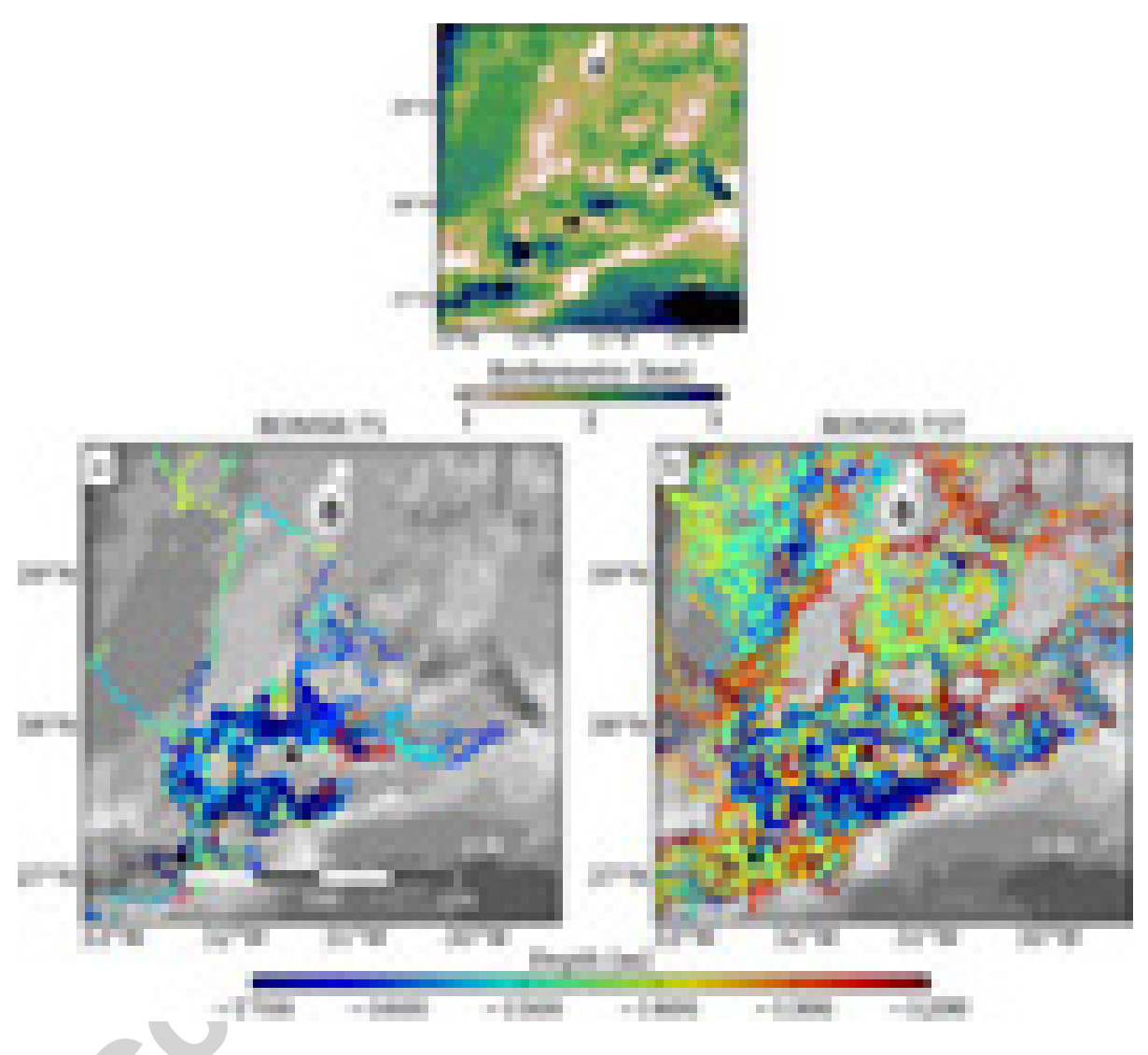

Figure 13: Subset of particle trajectories going to the northeast in (a) ROMS0.75 and (b) ROMS0.75T. The white star is the Lucky Strike site and black stars are the principal hydrothermal vents. Colors represent the depth of particles and background shades of gray is the model bathymetry with 500-m contour interval. Inset map on top shows the model bathymetry to emphasize topographic features. 
Observational (Thomson et al., 2003) and modelling (Young et al., 2008) studies underlined the paramount role of topographic steering to directionally bias the transport of passive larvae. Hence, representing the seafloor fine scales is of crucial importance to better quantify connectivity in ridge systems. The MAR's topographic structures are anisotropic with characteristic horizontal length scales $\lambda_{n}=7.1 \pm 1.0 \mathrm{~km}$ and $\lambda_{s}=20.8 \pm 3.1 \mathrm{~km}$ in the across- and along-ridge directions, respectively (see Table 4 in Goff, 1991). Increasing the model resolution allows to represent finer topographic scales. The two scales of topography $\left(\lambda_{n}, \lambda_{s}\right)$ are well resolved in ROMS0.75(T) and not, or poorly, resolved in ROMS6. Indeed, the bathymetry of ocean models is smoothed out at a scale of a few grid points to avoid too steep slopes leading to computational errors. Consequently, steeper topographic slopes are allowed in ROMS0.75(T) than in ROMS6, and the topographic steering of currents is better represented in $\operatorname{ROMS0.75}(\mathrm{T})$.

Due to $\lambda_{s}>\lambda_{n}$, indicating elongated structures in the along-ridge direction, currents are more likely to be topographically steered in the along-ridge direction. The along-ridge dispersion is thus likely to be enhanced compared to the across-ridge dispersion (Figures 11e,f and 12e,f).

Another effect of the highly-resolved bathymetry is to create steeper topographic slopes that can act as barriers for the particles. In particular, sub-basins of the MAR are resolved in ROMS0.75(T) (blue areas in Figure 13-inset). To investigate their role in the dispersion, we isolated two subsets of particles heading northeastward in ROMS0.75 and ROMS0.75(T). Particles were chosen to be at least $50 \mathrm{~km}$ away from the source at 30 days and to be situated to its northeast. In Figure 13, we restricted the subsets to have the same number of particles in ROMS0.75 and ROMS0.75T. In ROMS0.75, the sub-basins easily trap particles that are unable to cross the surrounding high topographic barriers (Figure 13a). Only a few particles escape through narrow passes, without experiencing a strong change in depth. On the contrary, in ROMS0.75T, tidal currents enhance the vertical dispersion, which allows particles to cross topographic obstacles (Figure 13b). These crossings are associated with strong 
vertical movements.

The different trajectories in ROMS0.75 and ROMS0.75T are further highlighted in the vertical plane (Figures 14 and 15). In ROMS0.75, the vertical position of particles is relatively steady and trajectories are mostly adiabatic, except close to rough topographic structures where particles can undergo diapycnal mixing and vertical movement due to lee waves (Viglione and Thompson, 2016) or submesoscale instabilities (Gula et al., 2016). In ROMS0.75T, particles systematically undergo strong mixing approaching steep topographic slopes, where energetic high-mode internal tides are generated (Vic et al., 2017). This change of density allows particles to rise up in the water column and cross topographic obstacles more easily.

These results likely explain why the cloud of particles is more spread in ROMS0.75T compared to ROMS0.75 (Figures 11c,d and 12c,d). Consequently, the effect of tides in the dispersion cannot be neglected in connectivity studies.

\section{Conclusions}

Using a series of regional numerical oceanic simulations, we have investigated deep currents over the MAR in the North Atlantic. Simulations have been thoroughly evaluated in the interior against observational datasets of different natures. They are found to (i) generate realistic mean currents, (ii) with realistic levels of turbulent energy (EAPE) at depth and (iii) decent internal (mostly tidal) wave activity. The Lagrangian dispersion of Lucky Strike vent products has been quantified using neutrally buoyant particles advected by the modeled currents. Results can be summarized as follows :

- We shed light on different regimes of oceanic turbulence at $1500 \mathrm{~m}$. The on-ridge regime is characterized by energetic submesoscale currents generation, due to frictional interactions with the topography. High Rossby numbers $|\zeta / f|>0.5$ are routinely observed and kinetic energy spectrum varies in $k^{-2.4}$, indicating significant departure from interior quasigeostrophic regime. On the contrary, the off-ridge regime is dominated by 


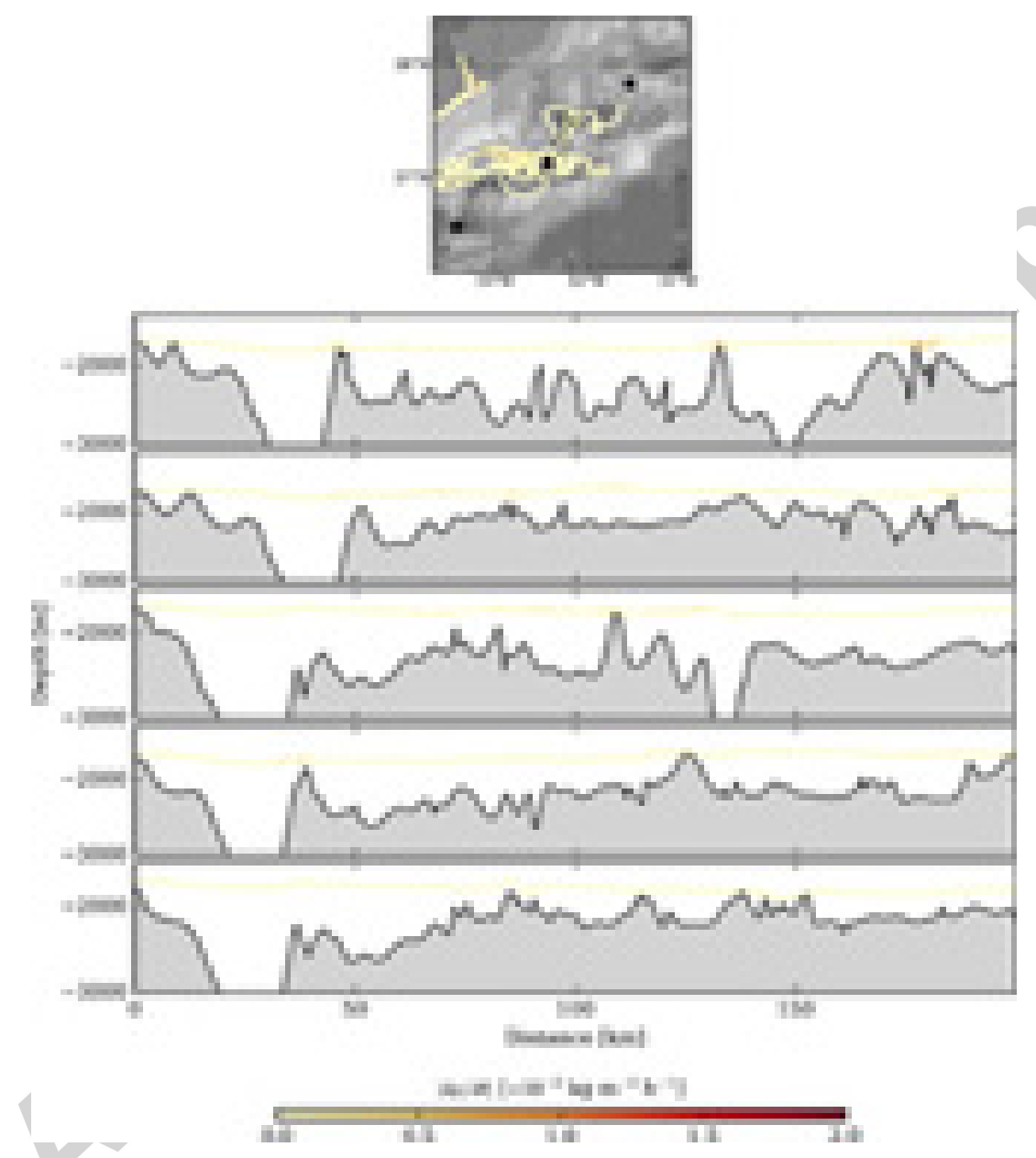

Figure 14: Subset of five particle trajectories in the horizontal plane (inset) and vertical plane. Colors represent the absolute rate of change of density $(|\partial \rho / \partial t|)$. In the inset map, the white star is the Lucky Strike site and black stars are the principal hydrothermal vents. 


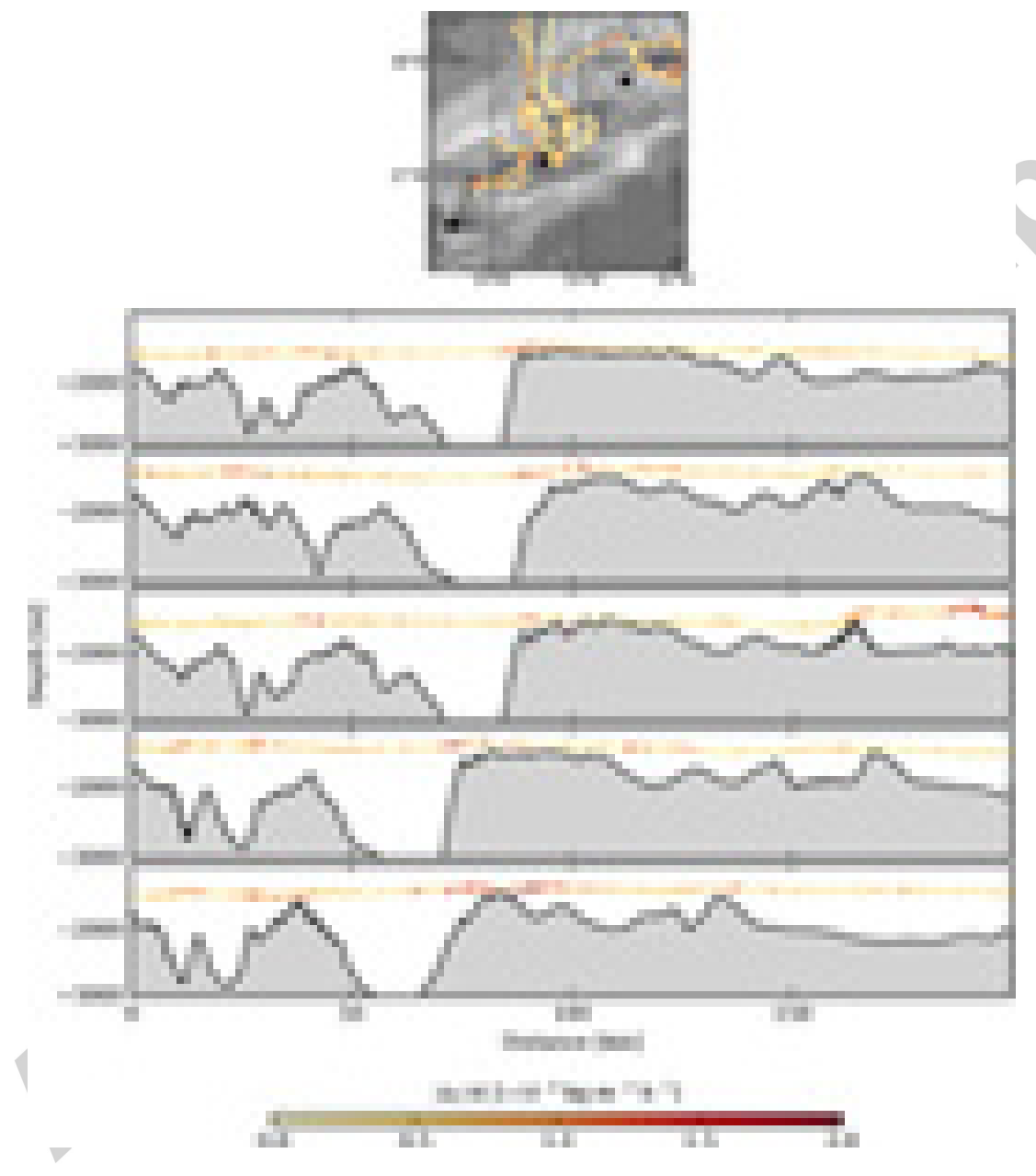

Figure 15: Same as Figure 14 for ROMS0.75T. 
mesoscales. Rossby numbers are in $O(0.1)$ and kinetic energy spectrum varies in $k^{-3.0}$, theoretically compatible with an interior quasi-geostrophic regime.

- Using a pair-dispersion analysis framework, we demonstrated the impact of submesoscale and tidal currents on the dispersion of particles. At small spatio-temporal scales - tens of kilometers and tens of days - submesoscale currents increase the relative diffusivity of the cloud of particles by one order of magnitude compared to mesoscale-resolving simulations. Tidal currents and internal tides do not significantly impact horizontal dispersion. However, they are found to dramatically increase the vertical dispersion of particles; the relative vertical dispersion is increased by a factor of 2-3 and the vertical eddy diffusivity is increased by one order of magnitude.

- Based on reproductive characteristics of the vent mussel Bathymodiolus, we investigated the impact of model resolution and tidal currents on absolute dispersion from Lucky Strike. Although the absolute dispersion is overall independent of the model resolution, submesoscales and tidal currents increase the mixing of the cloud of particles. As the mesoscale circulations were different in the $6-\mathrm{km}$ and $0.75-\mathrm{km}$ runs, we cannot be definite on an increased connectivity potential enabled by submesoscales. However, our submesoscale-resolving simulations suggest that the connectivity is enhanced between MAR hydrothermal sites (mainly, Saldanha and Rainbow) at PLD-relevant time scales. Notice that the long-term transport of material is partially performed by submesoscale coherent vortices. We thus mitigate the recent results of Breusing et al. (2016) who find that connectivity of larvae over one generation (one PLD) between known hydrothermal vents in unlikely.

- Importantly, our study highlights the hitherto overlooked impact of tides on dispersion. Tidally-induced mixing close to rough topographic features is found to play a crucial role in rising particles up in the water column, 
allowing them to cross topographic obstacles. Taking into account the effect of tides thus opens new trajectories for particles.

Overall, our study sheds light on how models' resolution and the range of resolved physical processes impact Lagrangian dispersion at depths of mid-ocean ridges. This case study on the MAR illustrates potential impacts on mussels' connectivity. Further impacts on hydrothermal effluents dispersion are also to

be expected. We thus advocate a careful design of oceanic circulation models to study Lagrangian dispersion in deep-sea environments.

\section{Acknowledgements}

This work is a contribution to the ANR project LuckyScales (ANR-14CE02-0008). Simulations were performed using HPC resources from GENCITGCC (Grant 2016-t2016017638). C. Vic and J. Gula acknowledge support from LabexMer. We thank J. Molemaker (UCLA and LOPS) for providing the ROMS6 outputs and A. Lough (NOCS) for useful comments on the manuscript. This manuscript benefited from thorough comments and constructive suggestions by three anonymous reviewers, we are grateful to their contributions.

\section{Appendix A. Sensitivity to the initial pair vertical position}

In our experiments, particles were initially released at depths spanning the plume vertical extent (-1800 to $-600 \mathrm{~m}$, Figure 7$)$. They are thus subject to different current speeds and directions. For connectivity purpose, we focused on a deep set of particles but the fate of other sets can be investigated, being relevant to vent geochemical effluents such as iron. To assess the influence of the initial depth $z_{i}$ on relative dispersion, we computed pair statistics for three different clusters, $z_{i} \in[-1800 \mathrm{~m},-1400 \mathrm{~m}], z_{i} \in[-1400 \mathrm{~m},-1000 \mathrm{~m}]$ and $z_{i} \in[-1000 \mathrm{~m},-600 \mathrm{~m}]$, released in ROMS0.75T (the most realistic simulation). Results are presented in Figure A.16.

The closest to the seafloor particles are, the fastest the horizontal relative dispersion (Figure A.16a). This is true at relatively short time $(<20$ days $)$ 

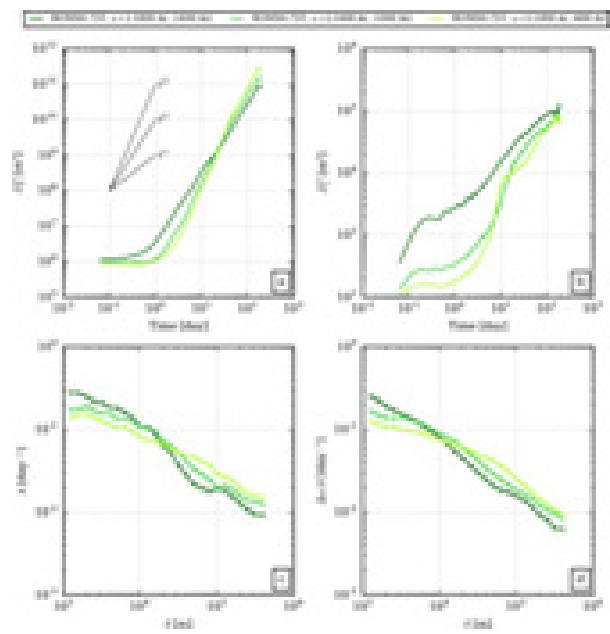

Figure A.16: Same pair statistics as in Figure 9 but for particles released at different depth ranges in ROMS0.75T : [-1800 m,-1400 m] (dark green lines), [-1400 m,-1000 m] (medium green lines) and [-1000 m,-600 m] (light green lines).

and spatial scales $(<10-20 \mathrm{~km})$. This result may be surprising since one may have expected topographic barriers to slow down the dispersion close to the seafloor. However, idealized numerical experiments previously demonstrated similar sensitivity (McGillicuddy et al., 2010; Mullineaux et al., 2013), with a dispersion systematically decreasing with height above the bottom (e.g., Fig. 5 in McGillicuddy et al., 2010). The bottom intensification of horizontal pair dispersion results from an enhancement of currents' amplitude and variability on the flanks of seamount-like structures. At larger spatio-temporal scales, the opposite holds : horizontal dispersion increases towards the surface because particles are more subject to surface-intensified mesoscale currents that increase their spreading rates.

Similarly, vertical dispersion is also maximum for the particles closest to the seafloor (Figure A.16b). This tendency lasts for the whole simulations and may be explained by the bottom intensification of internal tide activity. The MAR preferentially generates high-mode internal tides (St. Laurent and Garrett, 2002; St Laurent and Nash, 2004; Vic et al., 2017) with high vertical 
velocities and shear. They have the ability to vertically spread apart particle pairs and consequently increase the vertical eddy diffusivity towards the seafloor (Figure A.16d).

Topographic features such as ridges and seamounts are likely to impact vertical dispersion throughout the whole water column. Recently, seeding Lagrangian particles in a numerical model, Viglione and Thompson (2016) showed that enhanced upwellings in the Antarctic Circumpolar Current (ACC) occur downstream of major topographic features. Although processes responsible for mixing are different (lee waves in the ACC vs tidal waves over the MAR), particles might undergo strong vertical absolute dispersion over the MAR.

\section{References}

Arellano, S.M., Young, C.M.. Spawning, development, and the duration of larval life in a deep-sea cold-seep mussel. Biol Bull 2009;216(2):149-162. doi:10.1086/BBLv216n2p149.

Aurell, E., Boffetta, G., Crisanti, A., Paladin, G., Vulpiani, A.. Predictability in the large: an extension of the concept of Lyapunov exponent. J Phys A 1997;30(1):1.

Becker, J., Sandwell, D., Smith, W., Braud, J., Binder, B., Depner, J., Fabre, D., Factor, J., Ingalls, S., Kim, S., et al. Global bathymetry and elevation data at 30 arc seconds resolution: SRTM30_PLUS. Marine Geodesy 2009;32(4):355-371. doi:10.1080/01490410903297766.

Biscoito, M., Almeida, A., Segonzac, M.. Preliminary biological characterization of the Saldanha hydrothermal field at the Mid-Atlantic Ridge (36 34'N, $3226^{\prime} \mathrm{W}, 2200 \mathrm{~m}$ ). Cahiers de biologie marine 2006;47(4):421-427.

Bode, M., Bode, L., Armsworth, P.R.. Larval dispersal reveals regional sources and sinks in the Great Barrier Reef. Mar Ecol Prog Ser 2006;308:1725. doi:10.3354/meps308017. 
Bosse, A., Testor, P., Houpert, L., Damien, P., Prieur, L., Hayes, D., Taillandier, V., Durrieu de Madron, X., d'Ortenzio, F., Coppola, L., et al. Scales and dynamics of Submesoscale Coherent Vortices formed by deep convection in the northwestern Mediterranean Sea. J Geophys Res Oceans 2016;121(10):7716-7742. doi:10.1002/2016JC012144.

Bosse, A., Testor, P., Mayot, N., Prieur, L., D'Ortenzio, F., Mortier, L., Le Goff, H., Gourcuff, C., Coppola, L., Lavigne, H., et al. A submesoscale coherent vortex in the Ligurian Sea: From dynamical barriers to biological implications. J Geophys Res Oceans 2017;122(8):6196-6217. doi:10.1002/2016JC012634.

Bosse, A., Testor, P., Mortier, L., Prieur, L., Taillandier, V., d'Ortenzio, F., Coppola, L.. Spreading of Levantine Intermediate Waters by submesoscale coherent vortices in the northwestern Mediterranean Sea as observed with gliders. J Geophys Res 2015;120(3):1599-1622. doi:10.1002/2014JC010263.

Bower, A.S., Hendry, R.M., Amrhein, D.E., Lilly, J.M.. Direct observations of formation and propagation of subpolar eddies into the Subtropical North Atlantic. Deep Sea Res II 2013;85:15-41. doi:10.1016/j.dsr2.2012.07.029.

Bracco, A., Choi, J., Joshi, K., Luo, H., McWilliams, J.C.. Submesoscale currents in the Northern Gulf of Mexico: Deep phenomena and dispersion over the continental slope. Ocean Modell 2016;101:43-58. doi:10.1016/j.ocemod.2016.03.002.

Breusing, C., Biastoch, A., Drews, A., Metaxas, A., Jollivet, D., Vrijenhoek, R.C., Bayer, T., Melzner, F., Sayavedra, L., Petersen, J.M., et al. Biophysical and population genetic models predict the presence of "phantom" stepping stones connecting Mid-Atlantic Ridge vent ecosystems. Current Biology 2016;26(17):2257-2267. doi:10.1016/j.cub.2016.06.062.

Buckingham, C.E., Khaleel, Z., Lazar, A., Martin, A.P., Allen, J.T., Naveira Garabato, A.C., Thompson, A.F., Vic, C.. Testing Munk's hypothe- 
sis for submesoscale eddy generation using observations in the North Atlantic. J Geophys Res Oceans 2017;122(8):6725-6745. doi:10.1002/2017JC012910.

Callendar, W., Klymak, J., Foreman, M.. Tidal generation of large submesoscale eddy dipoles. Ocean Science 2011;7(4):487. doi:10.5194/os-7-4872011.

Cardona, Y., Ruiz-Ramos, D.V., Baums, I.B., Bracco, A.. Potential connectivity of coldwater black coral communities in the northern Gulf of Mexico. PloS one 2016;11(5):e0156257. doi:10.1371/journal.pone.0156257.

Charney, J.G.. Geostrophic turbulence. J Atmos Sci 1971;28(6):1087-1095.

Colaço, A., Martins, I., Laranjo, M., Pires, L., Leal, C., Prieto, C., Costa, V., Lopes, H., Rosa, D., Dando, P., et al. Annual spawning of the hydrothermal vent mussel, Bathymodiolus azoricus, under controlled aquarium, conditions at atmospheric pressure. Journal of Experimental Marine Biology and Ecology 2006;333(2):166-171. doi:10.1016/j.jembe.2005.12.005.

Conway, T., John, S.. Quantification of dissolved iron sources to the North Atlantic Ocean. Nature 2004;511:212-215. doi:10.1038/nature13482.

Cowen, R.K., Sponaugle, S. $\quad$ Larval dispersal and marine population connectivity. Annu Rev Mar Sci 2009;1:443-466. doi:10.1146/annurev.marine.010908.163757.

Cuvelier, D., Sarradin, P.M., Sarrazin, J., Colaço, A., Copley, J.T., Desbruyères, D., Glover, A.G., Santos, R.S., Tyler, P.A.. Hydrothermal faunal assemblages and habitat characterisation at the Eiffel Tower edifice (Lucky Strike, Mid-Atlantic Ridge). Marine ecology 2011a;32(2):243-255. doi:10.1111/j.1439-0485.2010.00431.x.

Cuvelier, D., Sarrazin, J., Colaço, A., Copley, J., Desbruyères, D., Glover, A.G., Tyler, P., Santos, R.S.. Distribution and spatial variation of hydrothermal faunal assemblages at Lucky Strike (Mid-Atlantic Ridge) revealed 
by high-resolution video image analysis. Deep Sea Res I 2009;56(11):20262040. doi:10.1016/j.dsr.2009.06.006.

Cuvelier, D., Sarrazin, J., Colaço, A., Copley, J.T., Glover, A.G., Tyler, P.A., Santos, R.S., Desbruyères, D.. Community dynamics over 14 years at the Eiffel Tower hydrothermal edifice on the Mid-Atlantic Ridge. Limnol Oceanogr 2011b;56(5):1624-1640. doi:10.4319/lo.2011.56.5.1624.

D'Asaro, E.A.. Observations of small eddies in the Beaufort Sea. J Geophys Res 1988;93(C6):6669-6684.

Debreu, L., Blayo, E.. Two-way embedding algorithms: a review. Ocean Dynamics 2008;58(5-6):415-428. doi:10.1007/s10236-008-0150-9.

Desbruyères, D., Almeida, A., Biscoito, M., Comtet, T., Khripounoff, A., Le Bris, N., Sarradin, P., Segonzac, M.. A review of the distribution of hydrothermal vent communities along the northern Mid-Atlantic Ridge: dispersal vs. environmental controls. Hydrobiologia 2000;440:201-216. doi:10.1007/978-94-017-1982-7_19.

Dewar, W., McWilliams, J., Molemaker, J.. Centrifugal instability and mixing in the California Undercurrent. J Phys Oceanogr 2015;45(5):12241241. doi:10.1175/JPO-D-13-0269.1.

Egbert, G.D., Erofeeva, S.Y.. Efficient inverse modeling of barotropic ocean tides. J Atmos Ocean Technol 2002;19(2):183-204. doi:10.1175/15200426(2002)019;0183:EIMOBO ¿2.0.CO;2.

Escartin, J., Barreyre, T., Cannat, M., Garcia, R., Gracias, N., Deschamps, A., Salocchi, A., Sarradin, P.M., Ballu, V.. Hydrothermal activity along the slow-spreading lucky strike ridge segment (mid-atlantic ridge): Distribution, heatflux, and geological controls. Earth Planet Sci Lett 2015;431:173-185.

${ }_{825}$ Geyer, W.R., Signell, R.P.. A reassessment of the role of tidal dispersion in estuaries and bays. Estuaries 1992;15(2):97-108. 
Goff, J.A.. A global and regional stochastic analysis of near-ridge abyssal hill morphology. J Geophys Res 1991;96(B13):21713-21737.

Green, J.M., Nycander, J.. A comparison of tidal conversion parameterizations for tidal models. J Phys Oceanogr 2013;43(1):104-119. doi:10.1175/JPO-D12-023.1.

Gula, J., Molemaker, M.J., McWilliams, J.C.. Submesoscale cold filaments in the Gulf Stream. J Phys Oceanogr 2014;44(10):2617-2643. doi:10.1175/JPOD-14-0029.1.

Gula, J., Molemaker, M.J., McWilliams, J.C.. Gulf Stream dynamics along the Southeastern US Seaboard. J Phys Oceanogr 2015a;45(3):690-715. doi:10.1175/JPO-D-14-0154.1.

Gula, J., Molemaker, M.J., McWilliams, J.C.. Topographic vorticity generation, submesoscale instability and vortex street formation in the Gulf Stream. Geophys Res Lett 2015b;42. doi:10.1002/2015GL063731.

Gula, J., Molemaker, M.J., McWilliams, J.C.. Topographic generation of submesoscale centrifugal instability and energy dissipation. Nat Commun 2016;7. doi:10.1038/ncomms12811.

Haza, A., Özgökmen, T., Hogan, P.. Impact of submesoscales on surface material distribution in a gulf of Mexico mesoscale eddy. Ocean Modell 2016;107:28-47. doi:10.1016/j.ocemod.2016.10.002.

Haza, A.C., Poje, A.C., Özgökmen, T.M., Martin, P.. Relative dispersion from a high-resolution coastal model of the Adriatic Sea. Ocean Modell 2008;22(1):48-65. doi:10.1016/j.ocemod.2008.01.006.

van der Heijden, K., Petersen, J.M., Dubilier, N., Borowski, C.. Genetic connectivity between North and South Mid-Atlantic Ridge chemosynthetic bivalves and their symbionts. PLoS One 2012;7(7):e39994. doi:10.1371/journal.pone.0039994. 
Husson, B., Sarradin, P.M., Zeppilli, D., Sarrazin, J.. Picturing thermal niches and biomass of hydrothermal vent species. Deep-Sea Res II 2016;in press. doi:10.1016/j.dsr2.2016.05.028.

Jackson, P., Ledwell, J., Thurnherr, A.. Dispersion of a tracer on the East Pacific Rise ( $9 \mathrm{~N}$ to $10 \mathrm{~N}$ ), including the influence of hydrothermal plumes. Deep-Sea Res I 2010;57(1):37-52. doi:10.1016/j.dsr.2009.10.011.

Klein, P., Hua, B.L., Lapeyre, G., Capet, X., Le Gentil, S., Sasaki, H.. Upper ocean turbulence from high-resolution 3D simulations. J Phys Oceanogr 2008;38(8):1748-1763. doi:10.1175/2007JPO3773.1.

LaCasce, J.. Statistics from Lagrangian observations. Prog Oceanogr 2008;77(1):1-29. doi:10.1016/j.pocean.2008.02.002.

LaCasce, J., Ohlmann, C.. Relative dispersion at the surface of the Gulf of Mexico. J Mar Res 2003;61(3):285-312. doi:10.1357/002224003322201205.

Ledwell, J., Montgomery, E., Polzin, K., St Laurent, L., Schmitt, R., Toole, J.. Evidence for enhanced mixing over rough topography in the abyssal ocean. Nature 2000;403(6766):179-182. doi:10.1038/35003164.

Lemarié, F., Kurian, J., Shchepetkin, A.F., Jeroen Molemaker, M., Colas, F., McWilliams, J.C.. Are there inescapable issues prohibiting the use of terrain-following coordinates in climate models? Ocean Modell 2012;42:5779. doi:10.1016/j.ocemod.2011.11.007.

Lilly, J.M., Rhines, P.B., Schott, F., Lavender, K., Lazier, J., Send, U.,

DAsaro, E.. Observations of the Labrador Sea eddy field. Prog Oceanogr 2003;59(1):75-176. doi:10.1016/j.pocean.2003.08.013.

Locarnini, R., Mishonov, A., Antonov, J., Boyer, T., Garcia, H., Baranova, O., Zweng, M., Paver, C., Reagan, J., Johnson, D., M, H., Seidov, D., et al. World Ocean Atlas 2013, Volume 1: Temperature. NOAA Atlas NESDIS 2013;73:40. URL: http://www.nodc.noaa.gov/OC5/indprod.htm. 
Mashayek, A., Ferrari, R., Merrifield, S., Ledwell, J.R., St Laurent, L., Naveira Garabato, A.. Topographic enhancement of vertical turbulent mixing in the Southern Ocean. Nat Commun 2017;8:14197. doi:10.1038/ncomms14197.

${ }_{885}$ Mason, E., Molemaker, J., Shchepetkin, A.F., Colas, F., McWilliams, J.C., Sangrà, P.. Procedures for offline grid nesting in regional ocean models. Ocean Modell 2010;35(1):1-15. doi:10.1016/j.ocemod.2010.05.007.

McGillicuddy, D.J., Lavelle, J.W., Thurnherr, A.M., Kosnyrev, V., Mullineaux, L.S.. Larval dispersion along an axially symmetric mid-ocean ridge. Deep Sea Res Part I 2010;57(7):880-892. doi:10.1016/j.dsr.2010.04.003.

McWilliams, J.C.. Submesoscale, coherent vortices in the ocean. Rev Geophys $1985 ; 23(2): 165-182$.

McWilliams, J.C.. Submesoscale currents in the ocean. Proc R Soc A 2016;472(2189):20160117. doi:10.1098/rspa.2016.0117.

895 Merrifield, M.A., Holloway, P.E. Model estimates of M2 internal tide energetics at the Hawaiian Ridge. J Geophys Res 2002;107(C8). doi:10.1029/2001JC000996.

Miyazaki, J.I., de Oliveira Martins, L., Fujita, Y., Matsumoto, H., Fujiwara, Y.. Evolutionary process of deep-sea Bathymodiolus mussels. PLoS one 2010;5(4):e10363. doi:10.1371/journal.pone.0010363.

Molemaker, M.J., McWilliams, J.C., Dewar, W.K.. Submesoscale instability and generation of mesoscale anticyclones near a separation of the California Undercurrent. J Phys Oceanogr 2015;45(3):613-629. doi:10.1175/JPO-D-130225.1.

905 Mullaney, T.J., Suthers, I.M.. Entrainment and retention of the coastal larval fish assemblage by a short-lived, submesoscale, frontal eddy of the East Australian Current. Limnol Oceanogr 2013;58(5):1546-1556. doi:10.4319/lo.2013.58.5.1546. 
Mullineaux, L.S., McGillicuddy, D.J., Mills, S.W., Kosnyrev, V., Thurnherr, A.M., Ledwell, J.R., Lavelle, J.W.. Active positioning of vent larvae at a mid-ocean ridge. Deep-Sea Res Part II 2013;92:46-57. doi:10.1016/j.dsr2.2013.03.032.

O'Connor, M.I., Bruno, J.F., Gaines, S.D., Halpern, B.S., Lester, S.E., Kinlan, B.P., Weiss, J.M.. Temperature control of larval dispersal and the implications for marine ecology, evolution, and conservation. Proc Natl Acad Sci 2007;104(4):1266-1271.

Ollitrault, M., Gabillet, C., Colin de Verdiere, A.. Open ocean regimes of relative dispersion. J Fluid Mech 2005;533:381-407. doi:10.1017/S0022112005004556.

Ollitrault, M., Rannou, J.P.. ANDRO: An Argo-based deep displacement dataset. J Atmos Oceanic Technol 2013;30(4):759-788. doi:10.1175/JTECHD-12-00073.1.

Poje, A.C., Haza, A.C., Özgökmen, T.M., Magaldi, M.G., Garraffo, Z.D.. Resolution dependent relative dispersion statistics in a hierarchy of ocean models. Ocean Modell 2010;31(1):36-50. doi:10.1016/j.ocemod.2009.09.002.

Poje, A.C., Özgökmen, T.M., Lipphardt, B.L., Haus, B.K., Ryan, E.H., Haza, A.C., Jacobs, G.A., Reniers, A., Olascoaga, M.J., Novelli, G., et al. Submesoscale dispersion in the vicinity of the Deepwater Horizon spill. Proc Natl Acad Sci 2014;111(35):12693-12698. doi:10.1073/pnas.1402452111.

Polzin, K., Toole, J., Ledwell, J., Schmitt, R.. Spatial variability of turbulent mixing in the abyssal ocean. Science 1997;276(5309):93-96. doi:10.1126/science.276.5309.93.

Renault, L., Molemaker, M.J., Gula, J., Masson, S., McWilliams, J.C.. Control and stabilization of the Gulf Stream by oceanic current interaction with the atmosphere. J Phys Oceanogr 2016;46(11):3439-3453. doi:10.1175/JPOD-16-0115.1. 
Reverdin, G., Gascard, J.C., Le Cann, B., Prieur, L., Assenbaum, M., Lherminier, P.. A long-lasting mode water vortex in the Northeast Atlantic Ocean. J Phys Oceanogr 2009;39(3):536-558. doi:10.1175/2008JPO3970.1.

Richardson, L.F.. Atmospheric diffusion shown on a distance-neighbour graph. Proceedings of the Royal Society of London, Series A 1926;110(756):709-737.

Risien, C., Chelton, D.. A global climatology of surface wind and wind stress fields from eight years of QuikSCAT scatterometer data. J Phys Oceanogr 2008;38(11):2379-2413. doi:10.1175/2008JPO3881.1.

Roullet, G., Capet, X., Maze, G.. Global interior eddy available potential energy diagnosed from Argo floats. Geophys Res Lett 2014;41(5):1651-1656. doi:10.1002/2013GL059004.

Scott, R.B., Arbic, B.K., Chassignet, E.P., Coward, A.C., Maltrud, M., Merryfield, W.J., Srinivasan, A., Varghese, A.. Total kinetic energy in four global eddying ocean circulation models and over 5000 current meter records. Ocean Modell 2010;32(3):157-169. doi:10.1016/j.ocemod.2010.01.005.

Scott, R.B., Furnival, D.G.. A guide to GMACMD. 2013. URL: http://stockage.univ-brest.fr/ scott/GMACMD/GMACMDdoc.pdf.

Shchepetkin, A., McWilliams, J.. The regional oceanic modeling system (ROMS): a split-explicit, free-surface, topographyfollowing-coordinate oceanic model. Ocean Modell 2005;9(4):347-404. doi:10.1016/j.ocemod.2004.08.002.

Shcherbina, A.Y., D'Asaro, E.A., Lee, C.M., Klymak, J.M., Molemaker, M.J., McWilliams, J.C.. Statistics of vertical vorticity, divergence, and strain in a developed submesoscale turbulence field. Geophys Res Lett 2013;40(17):4706-4711. doi:10.1002/grl.50919.

Smith, W., Sandwell, D.. Global sea floor topography from satellite altimetry and ship depth soundings. Science 1997;277(5334):1956-1962. doi:10.1126/science.277.5334.1956. 
Speer, K.G., Marshall, J.. The growth of convective plumes at seafloor hot springs. J Mar Res 1995;53(6):1025-1057. doi:10.1357/0022240953212972.

Sponaugle, S., Lee, T., Kourafalou, V., Pinkard, D.. Florida Current frontal eddies and the settlement of coral reef fishes. Limnology and Oceanography 2005;50(4):1033-1048. doi:10.4319/lo.2005.50.4.1033.

Sprung, M.. Reproduction and fecundity of the mussel Mytilus edulis at Helgoland (North Sea). Helgoländer Meeresunters 1983;36(3):242-255.

St. Laurent, L., Garrett, C.. The role of internal tides in mixing the deep ocean. J Phys Oceanogr 2002;32(10):2882-2899. doi:10.1175/15200485(2002)032¡2882:TROITI¿2.0.CO;2.

St Laurent, L., Nash, J.. An examination of the radiative and dissipative properties of deep ocean internal tides. Deep Sea Res II 2004;51(25):30293042. doi:10.1016/j.dsr2.2004.09.008.

Taylor, G.. Diffusion by continuous movements. Proc London Math Soc 1921;2(1):196-212.

Testor, P., Gascard, J.. Large-scale spreading of deep waters in the Western Mediterranean Sea by submesoscale coherent eddies. J Phys Oceanogr 2003;33(1):75-87. doi:10.1175/1520-0485(2003)033¡0075:LSSODW ¿2.0.CO;2.

Thomson, R.E., Mihály, S.F., Rabinovich, A.B., McDuff, R.E., Veirs, S.R., Stahr, F.R.. Constrained circulation at Endeavour ridge facilitates colonization by vent larvae. Nature 2003;424(6948):545-549. doi:10.1038/nature01824.

Thurnherr, A., Reverdin, G., Bouruet-Aubertot, P., St Laurent, L., Vangriesheim, A., Ballu, V.. Hydrography and flow in the Lucky Strike segment of the Mid-Atlantic Ridge. J Mar Res 2008;66(3):347-372. doi:10.1357/002224008786176034. 
Tyler, P., Young, C.. Reproduction and dispersal at vents and cold seeps. J Mar Biol Ass UK 1999;79(02):193-208.

Van Cosel, R., Comtet, T., Krylova, E.. Bathymodiolus (Bivalvia: Mytilidae) from hydrothermal vents on the Azores triple junction and the Logatchev hydrothermal field, Mid-Atlantic Ridge. Veliger 1999;42(3):218-248.

Van Dover, C.. The ecology of deep-sea hydrothermal vents. Princeton, NJ: Princeton University Press, 2000.

Van Dover, C.L.. Ecology of Mid-Atlantic Ridge hydrothermal vents. Geological Society, London, Special Publications 1995;87(1):257-294.

Veneziani, M., Griffa, A., Garraffo, Z.D., Chassignet, E.P.. Lagrangian spin parameter and coherent structures from trajectories released in a highresolution ocean model. J Mar Res 2005;63(4):753-788.

Colin de Verdière, A., Ollitrault, M.. A direct determination of the world ocean barotropic circulation. J Phys Oceanogr 2016;46(1):255-273. doi:10.1175/JPO-D-15-0046.1.

Vic, C., Naveira Garabato, A.C., Green, J.A.M., Spingys, C., Forryan, A., Zhao, Z., Sharples, J.. The lifecycle of semidiurnal internal tides over the northern Mid-Atlantic Ridge. J Phys Oceanogr 2017;in press. doi:10.1175/JPO-D-17-0121.1.

Vic, C., Roullet, G., Capet, X., Carton, X., Molemaker, M.J., Gula, J.. Eddy-topography interactions and the fate of the Persian Gulf Outflow. J Geophys Res 2015;120(10):6700-6717. doi:10.1002/2015JC011033.

Viglione, G.A., Thompson, A.F.. Lagrangian pathways of upwelling in the Southern Ocean. J Geophys Res Oceans 2016;121(8):6295-6309. doi:10.1002/2016JC011773.

Werner, F.E., Cowen, R.K., Paris-Limouzy, C.B.. Coupled biological and physical models - present capabilities and necessary developments for future 
studies of population connectivity. Oceanography 2007;20(SPL. ISS. 3):54-69. doi:10.5670/oceanog.2007.29.

1020 Wilson, C., Charlou, J.L., Ludford, E., Klinkhammer, G., Chin, C., Bougault, H., German, C., Speer, K., Palmer, M.. Hydrothermal anomalies in the Lucky Strike segment on the Mid-Atlantic Ridge $\left(37^{\circ} 17^{\prime} \mathrm{N}\right)$. Earth Planet Sci Lett 1996;142(3-4):467-477.

Worley, S., Woodruff, S., Reynolds, R., Lubker, S., Lott, N.. 1025 ICOADS release 2.1 data and products. Int J Climatol 2005;25(7):823-842. doi:10.1002/joc.1166.

Young, C., Fujio, S., Vrijenhoek, R.. Directional dispersal between mid-ocean ridges: deep-ocean circulation and gene flow in Ridgeia piscesae. Molecular ecology 2008;17(7):1718-1731. doi:10.1111/j.1365-294X.2008.03609.x.

${ }_{1030}$ Zhong, Y., Bracco, A.. Submesoscale impacts on horizontal and vertical transport in the Gulf of Mexico. J Geophys Res Oceans 2013;118(10):56515668. doi:10.1002/jgrc.20402.

Zweng, M., Reagan, J., Antonov, J., Locarnini, R., Mishonov, A., Boyer, T., Garcia, H., Baranova, O., Johnson, D., Seidov, D., et al. World Ocean Atlas 2013, Volume 2: Salinity. NOAA Atlas NESDIS 2013;74:39. URL: http://www.nodc.noaa.gov/OC5/indprod.htm. 